\title{
Value Congruence in Perception and Support of Organizational Visions
}

\author{
by \\ Kevin Leung \\ A thesis \\ presented to the University of Waterloo \\ in fulfilment of the \\ thesis requirement for the degree of \\ Master of Arts \\ in \\ Psychology
}

Waterloo, Ontario, Canada, 2012

(C) Kevin Leung 2012 


\section{Author's Declaration}

I hereby declare that I am the sole author of this thesis. This is a true copy of the thesis, including any required final revisions, as accepted by my examiners.

I understand that my thesis may be made electronically available to the public.

\section{Kevin Leung}




\begin{abstract}
Leadership scholars assume that the values espoused in an organizational vision have motivational effects on employee actions, but this claim has rarely been subject to empirical testing. Two studies examined whether organization members' support for organizational visions vary with the degree of congruence between members' personal values and the value-relevant impacts emphasized in a vision. Student participants learned of a visionary educational approach for universities, intended to impact either students' autonomy or their relatedness with other students. In Study 1, students who valued self-direction expressed most willingness to support the vision when autonomy-related outcomes were emphasized. Study 2 examined an apparent backfire effect in the first study, in which participants who value social belongingness expressed less willingness to support the vision when outcomes pertaining to relatedness were emphasized. This backfire effect, mediated through dis-identification with the vision, was found to be reversible when presentation cues that conflict with the stated values were removed.
\end{abstract}




\section{Acknowledgments}

I extend sincere gratitude to my advisor, Dr. John Michela, for his guidance and support with this paper. I am grateful for Dr. Erik Woody’s advice on statistics. A prior review of empirical research on vision, by Vivian Lo, has been quite helpful for this endeavor. I thank my parents, Norma and Shiu-Hong Leung, for their unwavering support of my academic pursuits. 


\section{Table of Contents}

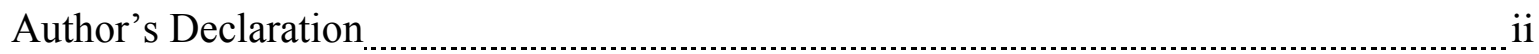

Abstract _

Acknowledgments

Table of Contents

List of Tables

List of Figures

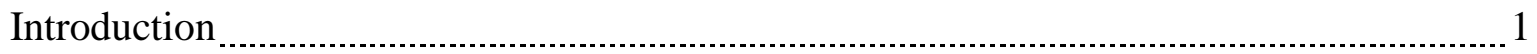

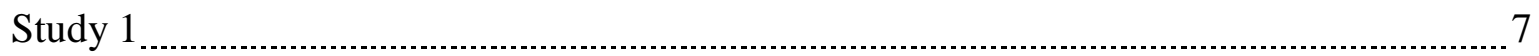

Method

Results

Discussion

Study $2 \ldots \ldots+2$

Method

Results

Discussion $\ldots \ldots \ldots$

General Discussion $\ldots \ldots \ldots \ldots$

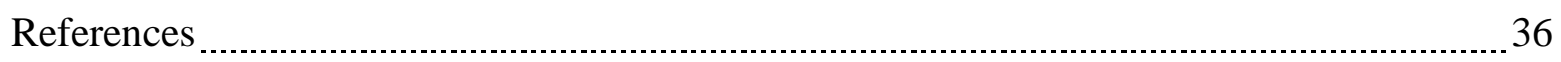

Appendices $\ldots \ldots \ldots$ 


\section{List of Tables}

Table 1: Means, Standard Deviations, and Intercorrelations _......................................... 42

Table 2: Standardized Canonical Discriminant Function Coefficients _............................... 43

Table 3: Regression Coefficients for Regression Analysis of Money Donation ................... 44

Table 4: Regression Coefficients for Regression Analysis of BSI (Study 1) _...................... 45

Table 5: A Comparison of the Three Versions of the Structural Equation Model ............... 46

Table 6: Confidence Intervals of the Standardized Indirect Effects (Study 1) _.................... 47

Table 7: Descriptive Statistics for Selected Study 2 Variables, Split by Condition _.............. 48

Table 8: Regression Coefficients for Regression Analysis of Manipulation Check ............. 49

Table 9: Regression Coefficients for Regression Analysis of BSI (Study 2) ...................... 50

Table 10: Regression Coefficients for Regression Analysis of Identification with Vision ... 51

Table 11: Confidence Intervals of the Standardized Indirect Effects (Study 2) 


\section{List of Figures}

Figure 1: Interaction of self-direction value $\mathrm{X}$ condition on money donation intent 53

Figure 2: Interaction of self-direction value $\mathrm{X}$ condition on money donation amount 54

Figure 3: Interaction of social belonging value X condition on BSI (Study 1) 55

Figure 4: Structural equation model depicting identification with vision as the mediator .... 56

Figure 5: Interaction of value orientation $\mathrm{X}$ condition on the manipulation check. 57

Figure 6: Interaction of value orientation X condition on BSI (Study 2) 58

Figure 7: Interaction of value orientation $\mathrm{X}$ condition on identification with vision. 59

Figure 8: Structural equation model depicting identification as the mediator (Study 2) 60 


\section{Introduction}

Organizations are faced with near-constant change (Cascio, 1995; Herscovitch \& Meyer, 2002). With the accelerated pace of technological development, globalization, and domestic competition, corresponding changes are often warranted in employees' work methods and priorities. While these behavioral changes hold great potential for greater productivity, leaders need employee buy-in and support if organizational changes overall are to yield their intended outcomes.

One starting point for a leader's effort to instigate and sustain change is the articulation of a compelling vision (e.g., Awamleh \& Gardner, 1999; Zaccaro \& Banks, 2004). An organizational vision is broadly defined as a description of an ideal or highly desirable state of the organization in the future that embodies shared values among members of the organization (Conger, 1989; Hauser \& House, 2000; Kouzes \& Posner, 1987). Past studies have shown that a leader's well-communicated vision can have positive effects on employee attitudes and performance (Dvir, Kass \& Shamir, 2004; Kirkpatrick \& Locke, 1996), as well as both direct and indirect links with increased organizational performance (Baum \& Locke, 2004; Baum, Locke \& Kirkpatrick, 1998; Zaccaro, 2001).

Although writers have postulated various attributes that a vision statement should contain—such as brevity, clarity, and abstractness (e.g., Baum et al., 1998; Hauser \& House, 2000) - these recommendations have rarely been subjected to empirical testing. This paper will describe two studies concerned with possible mechanisms and factors in the impacts of visions for organizational change. To guide the design of the first study, theoretical analysis is offered concerning motivational processes tied to the utility- and identity-linked consequences of human values as they relate to organizational visions. The second study was prompted by findings of the first, when particular perceptual processes appeared also to be pivotal in the impacts of organizational visions. 


\section{Motivation Arising from Visions}

Among the various recommended elements of a vision, personal or ideological values have been described as a key motivational component (Baum et al., 1998; Conger \& Kanungo, 1998; Hauser \& House, 2000; Kotter, 1990; Shamir, Arthur, \& House, 1994). For example, Kirkpatrick and Locke (1996) have characterized vision as "a general transcendent ideal that represents shared values; it is ideological in nature and has moral overtones" (p. 37). Zaccaro and Banks (2001) hold that a leader's appeals to the values that are promoted by a vision provide an avenue for persuasion by the leader, along with a potential source of passion for employees. Why might this be so?

Values and utility. Schwartz and Bilsky (1987) summarized five features of values, common to most definitions: "Values are (a) concepts or beliefs, (b) about desirable end states or behaviors, (c) that transcend specific situations, (d) guide selection or evaluation of behavior and events, and (e) are ordered by relative importance" (p. 551). Values can drive behavior (Rokeach, 1973), including workplace behavior (Schwartz, 1999). Living up to a value is compelling in part because it fulfills an abstract end state that one desires (Verplanken \& Holland, 2002). For example, individuals who value achievement are driven to its fulfillment by being ambitious and hardworking in their endeavors. Furthermore, values can guide one's evaluations of behaviors and events by their association with particular end states. Thus, values can influence one's choice of behaviors by determining the attractiveness of outcomes that are relevant to those values (Verplanken \& Holland, 2002). We will refer to this role of values in vision-linked motivation as utility-based.

Self, identity, and identification. Another possible basis for a motivational role of values within visions stems from the connection between values and self-concept (Hitlin, 2003; Hitlin \& Piliavin, 2004). Some of the ways in which the self-concept can motivate behavior involve the needs for self-consistency, self-expression, and maintaining and enhancing selfworth (Shamir, 1991; Shamir et al., 1994). Therefore when a vision concerns a highly valued end state, its pursuit provides an opportunity to satisfy these needs. 
Moreover, this analysis implies that one's identity can be reaffirmed by pursuit of a highly suitable vision — or by rejection of a highly unsuitable one. Thus we theorize that visions have the potential to draw upon identity-based motivation. In this conception, identity involves how a person differentiates the self from others as well as a person's integration with others in social groups (Tajfel \& Turner, 1979). This differentiation or integration must occur in terms of characteristics that are meaningful to the individual; underlying values can provide this meaning.

Identity also entails perceived differentiation or integration with other entities besides people (e.g., organizations), or even with "objects" that are meaningful for signifying "who I am." The process of such integration is identification. Differentiation, on the other hand, can take the form of dis-identification when someone declares (explicitly or implicitly) "who I am not." Thus, as Ashforth, Harrison, and Corley (2008) put it, identification occurs or is present when part of a person's identity incorporates some other entity, object, or activity. According to Dutton, Dukerich, and Harquail (1994), people forge this link to buttress their identities and, thereby, to satisfy self-concept-related needs as mentioned earlier. For example, someone's nascent identity as a supporter of the arts can be solidified through arts-related volunteer work, and through keeping that work salient within the self-concept.

Value congruence. A wide range of concepts underpins values - concepts such as loyalty, success, beauty, and justice. So far in this analysis, it has been implicit that people vary in terms of which values are highly central and which are therefore potent in utility- and identitybased motivation. In line with this thinking, values that are cognitively activated and highly central to the self have been found to elicit motivation and the regulation of value-congruent behaviors (Verplanken \& Holland, 2002). Thus a leader should be most able to draw upon valuebased motivation when the leader's vision concerns ends or means that are congruent with followers' values.

In other research domains, value congruence at a number of levels of specificity has been linked with important attitudinal and behavioral outcomes. Individuals prefer working in environments that promote values similar to the values that are personally important to them. In 
particular, value congruence between an organization and a job candidate has been linked to positive job choice intentions and later work attitudes, even when controlling for attractiveness of the job (Cable \& Judge, 1996). Value congruence between an employee and their organization has been linked to greater affective commitment to the organization (Abbott, White \& Charles, 2005), greater task and contextual performance (Goodman, \& Svyantek, 1999), and lower levels of stress (Bouckenooghe, 2005). A meta-analysis by Kristof-Brown, Zimmerman, and Johnson (2005) found that person-job and person-organization value congruence were significantly positively linked with job satisfaction and organizational commitment, and significantly negatively linked with intent to quit. Moreover, value congruence has been shown to be an important predictor of the success of mergers and acquisitions (M\&As). In an analysis of 59 M\&As, Daly and Pouder (2004) found that the congruence between the espoused values of firms pre-M\&A predicted post-M\&A financial performance.

\section{Empirical Study of Values as a Source of Motivation from Visions}

The centrality of the concept of values, in previous theoretical and prescriptive writings on vision-based motivation, has not been matched with a corresponding volume nor specific focus of empirical study of this matter.

Other researchers' studies. In two studies that looked for behavioral or performance effects of visions, appeals to values were examined along with other elements ascribed to visions. Choi (2007) surveyed employees in various units of a corporation, asking how strongly an organizational value was espoused within the organizational vision (with the value left unspecified — left for respondents to "fill in," so to speak). Choi also administered two additional items assessing strength of vision, not involving values explicitly. Vision strength predicted extent of employee suggestions for constructive change in work methods across organizational units, although this association was moderated by psychological empowerment and felt responsibility for change. In an experiment by Kirkpatrick and Locke (1996), participants heard either a visionary or non-visionary presentation by a leader (actually an actor) before the participants engaged in assigned tasks. The pertinent value in the visionary condition involved 
high quality of products produced, but the visionary condition also included expressions of confidence that participants could "do a super job" and other elements derived from charismatic and transformational leadership concepts. Task performance was only marginally higher in the condition in which a vision had been expressed by the leader (at $p=.07$, explaining $1 \%$ of variance). Larger effects of the vision-no vision manipulation were seen for attitudes and perceptions of the leader, including ratings of trust, inspiration, and perceived charisma.

Other studies that have examined perception of the more- or less-visionary leader include Frese, Beimel and Schoenborn (2003). These researchers assessed extent of value appeal as one of several aspects of "charismatic" communication behaviors (e.g., use of metaphor, gestures, positivity) exhibited by trainees in communication training. Peer ratings of the level of inspiration generated by trainees' presentations of visions showed generally positive associations with the various charismatic communication behaviors, although most of these associations (including for value appeal) did not reach statistical significance. In an experiment, Awamleh and Gardner (1999) sought to magnify extent of visionary content of a leader's message to followers by inclusion of references to values and moral justifications along with six other attributes such as reference to distal goals and the distant future. Attributions of charisma and leader effectiveness were associated positively and significantly with visionary content overall, although the specific contribution of references to values or moral justifications was not assessed. Similarly, Holladay and Coombs (1994) manipulated several "visionary" attributes of a leader's presentation —including reference to shared values_-finding positive effects on perceptions of charisma. Overall, to the extent that a more charismatically-perceived leader has more influence over followers, these latter studies suggest indirect support for a role for value congruence in motivation to pursue a vision.

In a study that did isolate value content in visions, Dvir, Kass, and Shamir (2004) assessed affective commitment toward the organization as an outcome. Employees in six firms rated the extent to which their CEOs mentioned achievement-related values (e.g., excellence, success) and social-related values (e.g., fairness, teamwork). Although greater mention of either 
of these kinds of values showed a positive, statistically significant, bivariate association with affective commitment, only social-related values explained unique variance in affective commitment when control variables and other predictors were also included in a multiple regression analysis. To the extent that affective commitment predisposes employees to work harder or smarter, this study points toward motivational impacts of visions' value content specifically. As noted by Dvir et al. (2004), the correlational nature of their study allows other potential bases of findings, such as a reverse causal influence from affective commitment to attributions of value content in leaders' messages. 


\section{Study 1}

The studies described in this paper extend a program of experimental research that has given focused attention to the value component of visions. A previous study provided direct support for a theory-derived prediction that greater salience of values in visions would generate greater support for the vision. Undergraduate student participants in research by Shipley and Michela (2006) viewed presentations about a vision for their community that portrayed a more healthful, environmentally responsible, and aesthetically-pleasing environment through creation of a network of bicycle paths. In a 2 X 2 design with random assignment, the salience of the values promoted by creation of bicycle paths was manipulated by including for approximately half of the participants, at the end of the presentation, a brief (less than ten seconds) but specific summary statement of the value-linked benefits of bicycle path creation (health, environment, and so forth); no corresponding statement was present for other participants. Value salience was also amplified for some participants by instructing some participants to discuss, after viewing the presentation, the extent to which they shared the values promoted by creating bicycle paths; other participants discussed implementation details such as how to overcome barriers to bicycle path construction. The two manipulations interacted such that participants who both heard the summary of values and discussed how the vision promoted their personal values were willing to donate the largest amount of money toward this vision. Additional, main effects were seen for the value summary manipulation in relation to a task given to participants. In connection with their course topic of "communication," participants worked together after the vision presentation to produce a communication plan for the vision. In the two conditions with the value summary, these plans were rated as higher in quality by the participants themselves and by research assistants kept blind to condition. Value summary condition participants also gave higher ratings of how "energetically" they had approached their assigned task. Thus this study provided experiment-based support for the theorized role of values on motivation, performance, and promotion of a vision. 


\section{Further Issues and Challenges for the Impact and Use of Value Appeals in Visions}

Appropriately for an experimental study, in Shipley and Michela (2006) the circumstances were ripe for detecting an impact of value salience. Key here was the high value congruence between the message or vision and the members of the audience. These students were enrolled in a course offered in the environmental studies division of a university - that is, in fields likely to attract students with values congruent with the vision of expanded bicycle paths. In contrast, organizational leaders may not have it so easy when they try to use visions to motivate action, because of the challenge posed by the variability of employees' personal values. Thus the present study's first objective was to examine what happens when a vision can be either congruent or incongruent with followers' values. The theoretical prediction (and thus the first hypothesis) is straightforward: with greater value congruence, greater support for the vision should be observed, and greater incongruence should yield either diminishing support or increasing opposition.

A related issue connected with leadership in organizations is that the encompassing, valued ends that can be sought by pursuing an organizational vision may tend to lack the motivational force of visions in other spheres such as communities (e.g., bicycle paths with their connections to environmental stewardship) or national politics ("Yes we can."). Consequently in our further experimental studies with undergraduate student participants we presented visions designed to have impacts on students' work activities as students (i.e., the work of learning individually and in groups) and thus on value alignment or misalignment. Precedents for creating organizational analogues within classroom settings for research purposes include research by Gruenfeld, Mannix, Williams, and Neale (1996) who conducted an experiment with student groups to understand decision-making processes within teams in organizations. In our study, our intention was to demonstrate that values pertinent to work can function within work- or organization-related visions to influence vision buy-in or promotion for the vision.

In the theoretical analysis offered earlier that concerned how values come into play, utility- and identity-based processes each were sketched. Previous studies do not isolate one or 
the other of these two categories as explanatory. Such isolation is a very challenging task because theory can imply that they generally work together. For example, an increase in one's sense of self-worth through identification with a vision generally requires that the vision's ends are valued - thus being perceived with high utility. Nonetheless, a further objective of the present research was to begin this isolation by looking specifically for identity-linked influence. Thus we predicted (hypothesized) that value congruence's ultimate motivational effects are associated with identification, in the form of mediation by identification.

\section{Means of Addressing the Key Issues and Challenges}

Given these objectives, the research required the production of work- and organizationrelevant visions with distinct value emphases. For the particular value emphases expressed in the visions there needed to be corresponding personal value distinctions within the student population, so that value congruence/incongruence could be examined. In order to accomplish an analogue to private- and public-sector work organizations, the particular values had to be pertinent to non-student work as well.

Bases for values used. The two value concepts that we selected concern autonomy and relatedness. Several prominent lines of motivation-related theory and research in personality, social, and organizational psychology support our initial presumptions that these value concepts are potent, distinct, and broadly applicable_-yet variable in strength among people (allowing detection of associations with congruence as such).

Self-Determination Theory (SDT) (Deci \& Ryan, 2002) identifies three major needs which provide motivation for self-initiated, intrinsically motivated activity. These three needs are autonomy, relatedness, and competence. The first two of these correspond with the two value concepts selected for our research. In addition, various needs-based theories, focusing more specifically on the workplace, highlight autonomy or relatedness in various ways. For example, in Hackman and Oldham's (1980) job characteristics theory, autonomy is one of the key contributors to "motivating potential." In Alderfer's (1969) prominent "ERG" theory of basic human needs, pertinent to the workplace, "R" stands for social Relatedness. 
Seeking insight into motivational differences across cultures, Markus and Kitayama (1991) distinguished independent self-construal from interdependent self-construal. One distinguishing characteristic of people with greater independent self-construal is their perceptions of themselves as relatively autonomous. People with greater interdependent self-construal instead are attuned to their relatedness with others, as manifested, for example, in the salience they hold for their role relationships, as with family members.

We do not mean to suggest that a one-to-one correspondence exists between the preceding concepts and the values that we sought to activate, and we are well-aware that there are important distinctions between, for example, the concepts of autonomy in SDT and in independent self-construal. Nevertheless we took these two broad categories of autonomy and relatedness as a starting point for looking for corresponding value "regions" and placements of specific value terms in the spatial representations of personal values provided by Schwartz (1992). Based on empirical data from large-scale cross-cultural studies, Schwartz (1992) identified 10 value regions (e.g., Tradition, Achievement, Universalism) that are arrayed about a generally circular structure (i.e., lying on a geometric plane). The values in adjacent regions tend to be correlated (i.e., rated similarly), whereas values that are farther away-especially in opposition across the circle — tend to be uncorrelated or negatively correlated (Arthaud-Day, Rode, \& Turnley, 2012).

Autonomy, broadly conceived, falls within the region labeled "Self-direction." Specific value concepts commonly assessed by Schwartz (1994) within this region include "choosing own goals" and "independent." Relatedness as we conceptualize it spans two regions that are not adjacent to Self-direction. One region is labeled "Benevolence" and includes "True friendship" as a specific value. The other region, approximately in opposition to Self-direction, is labeled "Security" and includes "Sense of belonging."

Operationalization. While seeking to assess values in the domains of autonomy and relatedness, our operationalization of the corresponding measure of personal values did not hew to the specific terms of Schwartz (1992), due to the need for their alignment with the particulars 
of the visions promoting one or the other value. In order to bolster the intended organizational analogue, the visions concerned potentially beneficial changes in how students would do their work (e.g., "acquire course content information"), tied to technological change. Specifically, both visions described a vision of "E-learning," in which course lectures would be "streamed" from a server computer when and where desired; class time would be used more for interaction among students or with the instructor instead of for receiving lecture; and other supports would be provided (e.g., enhanced digitized resource availability). The two vision conditions differed in the prominence given to the consequences of the changes for autonomy or relatedness.

\section{Method}

\section{Participants}

Participants were 182 undergraduate students enrolled in an introductory Human Resource Management course at a large (34,000 student) Canadian university. Approximately $57 \%$ of students in the class were male. Participants were randomly assigned to one of the two experimental conditions - one emphasizing autonomy-related consequences and the other emphasizing consequences about relatedness.

\section{Materials}

Vision of E-learning videos. The two visions were delivered as pre-recorded, voiceover-slides presentations. In most regards the two presentations were identical, and each lasted approximately six minutes. Both began by defining E-learning in general and discussing how the use of E-learning tools is a growing trend in education and industry. Next they introduced "a new vision of E-learning" for the university, involving the increased use of E-learning tools in lecture-based courses to supplement and enhance classroom learning. Further details about this initiative were given in both conditions. These include the use of online learning programs, the re-designed use of class time after moving some content coverage online, and enhancements to the university's digital resources to support the E-learning initiative.

The two experimental conditions differed near the end of the presentations, when the initiatives' expected outcomes were highlighted. In the autonomy condition, it was explicitly 
stated that the initiative would support more autonomous, self-directed learning. This statement was supported by explaining that the online learning programs would support the creation and tracking of self-set learning goals, and that the enhanced digital resources would support convenient, autonomous learning. Conversely, in the relatedness condition, it was explicitly stated that the initiative was expected to support more interaction, connection, and collaboration among students. This statement was supported by explaining that the re-designed use of class time would allow for more interaction and discussion during class, and that the online learning programs would support collaborative project work and facilitate student discussions.

\section{Measures}

Personal value ranking. A list of eight value statements appeared on a questionnaire that was administered before the vision presentation. Participants were asked to rank the statements according to the extent to which "the value reflects who you are and what you care about." Each value statement consisted of a term followed by a short explanation to illustrate the term's meaning. Two statements assessed autonomy-related values: "Self-direction (self-reliance, being able to manage yourself)" and "Personal autonomy (freedom in actions, being able to do things your own way)." The two statements that assessed relatedness values were "Social belonging (to be included, to feel connected, to feel part of a group)," and "Social connection (friendship, companionship, collaboration)." The remaining four statements were "fillers" (interspersed), worded as: "Equality in society (equal opportunity for all)," "Personal success (achievement, a prosperous life)," "Social justice (fair and unbiased outcomes for all)," and "Personal recognition (gaining respect and admiration)."

Money donation intentions. This and the remaining measures were administered after the vision had been presented. Participants' motivation to support the vision was measured first by asking participants whether they would be willing to have their student fees increased to support the implementation of the E-learning at the university (yes/no), and if "yes," what amount they would donate. 
Behavioral support intentions. Motivation to support the vision was also measured with an eight-item questionnaire asking participants (using a yes/no response scale) whether they would be willing to perform various actions to promote the initiative (cf., Ratner \& Miller, 2001). These behaviors varied in the amount of time or effort required. An example of a more effortful item is "Distribute and/or post flyers on campus advertising courses that incorporate ELearning." An example of a less effortful item is "Sign a petition to encourage greater use of ELearning at [the university]." Cronbach's alpha was .75.

Identification with vision. Participants' identification with the E-learning vision was measured using a ten-item scale (Appendix A) developed for this study, based primarily on the writings on identification by Ashforth and Mael (1989), Pratt (1998), and the Mael scale of organizational identification (Mael \& Tetrick, 1992). Central concepts from these sources include recognizing a similarity in important underlying ideals, feeling a sense of pride, and desiring public awareness of your connection with the object of identification (in this case, the Elearning vision). Example items targeting these concepts are, respectively, "The ideals in the vision match up well with my own ideals," "I would be proud if the University made this vision a reality," and "I would be happy to have other people know that I support this vision" respectively. Cronbach's alpha was .92 .

Manipulation check. An eight-item manipulation check scale was designed, with two items targeting information given in the autonomy condition presentation, two items targeting information given in the relatedness condition presentation, and four filler items. An example item targeting the autonomy presentation is "The proposed online learning programs would help students utilize self-set learning goals." An example item targeting the relatedness presentation is "The proposed E-learning online programs would support collaborative project work."

\section{Design \& Procedures}

Data were collected during a class meeting of a Human Resources Management course. When students arrived at their usual lecture hall they were randomly assigned to one of the two presentation conditions by providing each student with a slip of paper stating their "group" 
assignment. This condition assignment was balanced across genders by using a different set of these slips for each gender. The students were told that the researcher was doing a study on communication and motivation which included a presentation on E-learning. It was stated that participation in the study was completely voluntary and that students could watch the E-learning presentation regardless of whether they chose to complete any study measures. After allowing for clarifying questions, the researcher asked students who had been assigned to "group 2" to move to another room.

A materials packet was then given to all participants, with the pre-presentation materials attached to an envelope containing the post-presentation questionnaire measures. The postpresentation measure packet was in a sealed envelope to ensure participants would not read or begin the measures until instructed to do so after the vision presentation was complete. The prepresentation material packet contained a study information letter, informed consent form, and the personal value ranking measure. The researcher began the E-learning vision presentation video, appropriate to the given condition, after all participants had dealt with the pre-presentation materials. After the presentations were complete, the researcher instructed the participants to open and complete the questionnaires in the sealed envelope. Once these post-measures were complete they were returned to the researchers in individual envelopes, and then the researchers debriefed the participants.

\section{Results}

\section{Descriptive Statistics}

Means, standard deviations, and correlations are presented in Table 1. There were no significant correlations between the experimental condition and any of the value rankings, indicating that random assignment was successful.

After eliminating 14 participants with large amounts of missing data, 168 participants were retained. Responses concerning amount of money donation amount had large variability $[M=10.26, S D=34.49]$, so a $\log$ transformation of the raw dollar amounts was performed before analysis. 


\section{Manipulation Check}

Discriminant analysis was used to obtain a joint analysis of the relation between the four manipulation check items and the two conditions (see Table 2). This analysis yielded a statistically significant Wilk's lambda of .94 $(p<.05)$. Condition means took their expected patterns (e.g., with higher means in the autonomy-highlighted condition for agreement that "The proposed E-learning programs will support autonomous learning."). Thus there was evidence that participants, overall, received somewhat different messages between the conditions, as intended.

\section{Calculation of an Attention Variable}

Having seen some indications of disengagement among some participants (the 14 disqualified ones) in the classroom context of the experiment, it seemed warranted to create an index of engagement applicable to all participants, for use as a control variable. For this purpose, attention to the presentation was scored on the basis of the same four items as for the manipulation check. Because the discriminant analysis had produced an optimal weighting scheme for the items (i.e., one that maximizes the difference between conditions), that weighting scheme and its resulting discriminant function score were used in the production of the attention variable.

Application of these weights, shown in Table 2, produces a score that is high if a participant gave high ratings to the items targeting the relatedness condition and low ratings to the items targeting autonomy. For participants in the relatedness condition this score is immediately interpretable as an indicator of attention, and for participants in the autonomy condition the signs of the weights were reversed to produce a parallel indicator of attention.. This variable is hereafter referred to as attention.

Value Congruence Hypotheses Tests

Value congruence was operationalized within multiple regression (MR) analysis as the two-way interaction term for experimental condition and personal value ranking. Other predictors in the regression design were attention and all of its cross-product terms (thus 
producing a complete 3-way design with, of course, all subordinate linear and 2-way terms). Because linear terms were mean centered before entering them into the MR equation or using them to produce cross product terms, simultaneous MR was sufficient for conducting appropriate tests. Separate MR analyses were conducted not only for each outcome variable but also for each personal value separately. The rationale for separate analyses for the four target variables, instead of a single joint analysis, grows out of the inter-correlations of the personal values shown in Table 1. Seemingly similar personal values do not show high correlations with one another in that table, potentially undermining joint analyses. (Part of the reason for low correlation is the impossibility, by design, of ranking more than one value most highly.)

"Self-direction" value. The logistic regression analysis revealed a significant interaction between condition and self-direction value on money donation intention (Wald test $=4.87, p=$ .027). Figure 1 illustrates this interaction by showing the percentages of categories of people who stated an intention to make a donation toward E-learning. Categorization as low or high on selfdirection value was by median split. In the value-congruent condition for this value, the autonomy condition, donation intent increased with increasing personal value; in the absence of value congruence, donation intent decreased.

The MR analysis for prediction of money donation amount provided consistent though only marginally statistically significant findings. As shown in Table 3, the interaction of condition $\mathrm{X}$ personal value for self-direction yielded $t(156)=-1.70, p=.09$. Figure 2 illustrates this interaction. The pattern is, not surprisingly, much like that of Figure 1 for the binary variable, showing increasing donation amounts with higher congruent value, and decreasing donation amounts otherwise. Tests were conducted for the simple slope for self-direction value in each condition, but neither yielded statistical significance. As noted with Table 3, the test result for the joint association of all predictors with money donation amount was not statistically significant. However, the other predictors besides the interaction of condition and personal value were not intended to "explain variance" but, instead, to control for attention or ensure the validity 
of the interaction test which, as reported earlier, reached $\mathrm{p}<.10$ for money donation result and $\mathrm{p}$ $<.05$ for the binary variable.

The other MR analyses involving the self-direction value and its counterpart, "Personal autonomy," did not yield statistically significant effects corresponding to vision-value congruence.

"Social belonging" value. As presented in Table 4, the condition X social belonging value interaction term as it predicted behavioral support intentions yielded statistical significance $(t(163)=-2.03, p=.044)$. This result (Figure 3) was opposite to prediction; participants who ranked social belonging with low importance were more likely to endorse behaviors supporting the E-learning initiative if they were in the condition that did not emphasize relatedness outcomes. The simple slope in the autonomy condition was not statistically significant $(t(163)$ $=-0.57, n s)$, whereas the simple slope in the relatedness condition was statistically significant $(t(163)=-2.69, p<.01$.) Subsequent analyses with structural equation modeling (SEM) were conducted to shed light on this result. The simultaneous regression with all seven predictors yielded $\mathrm{R}^{2}=.110, \mathrm{~F}(7,162)=2.729, p=0.011$. The other MR analyses involving the social belonging value and its counterpart, "Personal autonomy," did not yield statistically significant effects corresponding to vision-value congruence.

\section{Mediation Hypotheses Tests with Structural Equation Modeling}

A structural equation model was constructed to examine participants' identification with the vision as a potential mediator between their social belongingness value ranking and behavioral support intentions. The overall structure of our SEM analyses, implemented with AMOS software (Arbuckle, 1989) is shown in Figure 4. Social belongingness value was modeled as the exogenous variable. Behavioral support intentions provide the final outcome in this model, and it was constructed by a parceling method (three indicators were formed as means of 2 or 3 items from the questionnaire). Identification with vision is the mediating variable in this model, and it was also constructed by a parceling method. 
We began by constructing alternate versions of the model in Figure 4. In one version, all the paths are fixed (equated) between the two presentation conditions. In a second version, the path from social belonging value to identification with vision is not fixed between the two conditions.

As indicated in Table 5, the difference between these two versions of the model in overall $\chi^{2}$ is 5.86 with a $1 \mathrm{df}$ difference, which exceeds the critical value of 3.84 for $p<.05$. Hence, we selected the model with the better fit of the two, which in this case, is when the path is different between the two conditions. Next we considered whether the remaining structural paths should vary between the two conditions and constructed a third version of the model. As indicated in Table 5, the difference between versions 2 and 3 in overall $\chi^{2}$ is 0.47 with a $2 \mathrm{df}$ difference, so it does not reach the critical value of 3.84 for $p<.05$. Because versions 2 and 3 are not significantly different from each other, we selected version 2 for the remaining mediation analysis by indirect effects tests.

The paths estimated in version 2 of the model are shown in Figure 4 as standardized coefficients. The model evidenced good fit with the data, with $\chi^{2}(32, \mathrm{~N}=173)=41.05, p=.13$. The ratio of $\chi^{2}$ to df was 1.28 , with $\mathrm{CFI}=.99$, and $\mathrm{RMSEA}=.04$.

We defined additional estimands in AMOS to assess and compare the two experimental groups' indirect pathways from social belongingness value to behavioral support intentions. As shown in Table 6, the 95\% upper and lower bounds of the confidence interval of the indirect effects parameters (obtained by bootstrapping) include 0 for the autonomy condition, but not for the relatedness condition. Therefore, in the relatedness condition, there was a significant indirect effect from social belonging value to behavioral support intentions. Specifically, the social belonging value is negatively associated with identification with the vision, which in turn is positively associated with behavioral support intentions.

\section{Discussion}

We obtained a mixture of support and contradiction for our first hypothesis, concerning value congruence. As predicted, when the vision presentation emphasized the autonomy 
afforded, people who had expressed higher value on self-direction were more likely to indicate that they would donate money toward the vision. Contradictory findings were connected with the vision presentation emphasizing relatedness, where value congruence in terms of social belonging predicted lower intentions to give behavioral support for the vision. In other words, the claims of expanded relatedness in the corresponding vision presentation appeared to "backfire" among people holding the corresponding value.

Support was obtained for the second hypothesis, concerning a mediating role of identification, although the form taken by this support was not as expected. Specifically, the structural equation model indicated that participants with high relatedness value dis-identified with the relatedness vision, and this dis-identification mediated part of the association between endorsement of the social belonging value statement and a low level of behavioral support.

The obtained backfire effect led us to re-view the recorded vision presentation that emphasized relatedness, trying to imagine what there could be in its form or content that repelled people with relatedness value. Our observation was that computers may have appeared dominant over people in the framing and imagery of the presentation, if not the message. For example, the vision was framed or labeled as "E-learning." In images containing people working together at tables in a classroom, portable computers were also visible in front of most of the people. Thus our inference was that participants with high relatedness value rejected the explicit message in light of other cues.

Research in persuasive communications and marketing has documented various initially surprising effects of cues including backfire effects. For example, Raghubir and Celly (2011) showed that the visual size of a free gift that accompanies a potential item for purchase should be small, not large, because the quality of the item is inferred to be lower with the larger gift image. Post hoc this result is understandable from various perspectives (e.g., attribution theory), yet the point remains that a priori it is difficult to predict fully how a multifaceted communication will be perceived and received by an audience. The presentation of a vision is a complex 
communication exercise that involves not only the semantic message, but also cues in the form of images, framing, and other stimuli which can either enhance or diminish value congruence.

Actual advertisers evidently agree with this analysis, given findings of a study of selfconstrual and advertising, by Stephens, Markus, and Townsend (2007). As mentioned in the introduction, self-construal varies between a predisposition for independence, which emphasizes individual uniqueness and distinction from others; and interdependence, which emphasizes conformity and a desire for commonality with others (Markus and Kitayama, 2003). In a study of automobile advertisements targeted at either working-class Americans (who tend to value interdependence) or middle-class Americans (who tend to value independence), Stephens et al. (2007) found that advertisements targeted at the working-class tend to place greater emphasis on interdependence, as by including more images of people and more texts that mention friends or family. On the other hand, advertisements targeted at the middle-class tend to place greater emphasis on uniqueness and deviation from norms, as by including messages such as "Only one of its kind in the world" and "No two will ever be the same," and also by having fewer images of people. Indeed, marketers strategically use both semantics and cues in advertisements to connect with the preferences of their target groups, suggesting that cues are part and parcel of the operative elements in persuasive communications.

Applying this thinking to visionary communications, we propose that the inclusion of value-congruent cues (and, by extension, the removal of value-incongruent cues) can enhance the perception of congruence with the valued ends that are being promoted, thus affecting the level of support for a vision. Study 2 will examine this proposition.

Before presenting Study 2, three further issues from Study 1 should be addressed. First is the fact that of the two available indicators of support for the vision-money donation and actions on its behalf — only one had the predicted association in relation to the autonomy domain, and the other one had the contrary association involving relatedness. In our previous research using vision presentations (e.g., Shipley \& Michela, 2006) it has also been the case that we have 
not been able to predict which kind of vision support indicator would yield meaningful findings. Thus for Study 2 we again administered both kinds of measures.

However, a change was made between the two studies in the measurement of personal values. We had been unable to predict which of two intended indicators of personal values in the autonomy and related domains would yield meaningful findings, and the use of a ranking form of measurement was suspected as a factor in this outcome. Thus a different form was devised.

A further change was to provide vision presentations in a setting that would be likely to obviate the need for the somewhat complex measure of attention to the vision presentation. Although the presentations were, again, pre-recorded, the experimenter was present with participants in much smaller groups — a procedure which has improved attention in our previous studies. 


\section{Study 2: Eliminating the Backfire Effect}

The purpose of this study was to garner support for our theoretical analysis of the perceptual basis of the "backfire" effect obtained in the previous study. We sought to replicate this backfire effect in one experimental condition but eliminate it in another by changing the framing and other perceptual cues pertinent to the promotion of relatedness values in the vision presentation. These cues, including photographic images and presentation title, were altered in an attempt to avoid undermining the semantic content stating that the vision promoted relatedness value. As previously suggested, cues in the vision intended to promote relatedness value may have been misaligned by signaling an emphasis on the computer technology that was part of the new way of working (learning) in the vision.

Given the foregoing, the basic hypothesis of Study 2 was: Alignment of the implied meanings of perceptual cues with semantic content in favor of a value promoted in a vision will increase the level of support for the vision among people who hold that value.

It was of further interest whether: Among people who hold a value that is congruent with the semantic content of a vision, and in the presence of perceptual cues with meanings that are inconsistent with the value promoted explicitly in a vision, dis-identification with the vision will partly explain (i.e., mediate) decreased support for the vision.

\section{Method}

\section{Participants}

Participants were 91 undergraduate students (66\% female) enrolled in psychology courses who participated in the study in exchange for course credit.

\section{Overview}

This study consisted of two conditions labeled as "E-Learning" and "Blended Learning." E-Learning is a close replication of the relatedness condition in Study 1 with slight modifications to slide formatting (e.g., PowerPoint ${ }^{\mathrm{TM}}$ "theme," for consistency with the new condition and to new software versions). Blended Learning is an alternative condition promoting relatedness, placing less emphasis on the non-social elements of using online learning tools. Both visions 
were delivered to small groups as a ten-minute, ten-slide PowerPoint ${ }^{\mathrm{TM}}$ presentation in which the experimenter followed a script to ensure consistency. To emphasize relatedness values, both versions of the presentation concluded with expected outcomes expressing "more interaction, connection and collaboration" between students. Promotion of these outcomes was expressed by stating that students would have more class time for interactions and discussions with their peers and instructors, thereby enabling more social connections.

The Blended Learning condition differs with the following modifications to deemphasize perceptual cues about non-social elements of online education. (1) To avoid invoking pre-conceived notions of online education, the term "blended-learning" was used in place of "Elearning" in the title and at other points in the presentation. (2) Indications that the vision would isolate people in front of their computers were removed (e.g. photos of individuals in front of computers — as displayed on presentation slides_-were replaced).

Because expanded use of computer technology is, in fact, a necessary part of the vision, and because we suspected that people with high relatedness values had regarded its expansion as inherently socially isolating, one change was made to the content of the presentation in the Blended learning condition compared with the E-learning condition. Specifically, more details were given about the social interaction that would occur given this vision (e.g., group activities that could occur during class time in place of instructor lecture).

\section{Measures}

The same measures from Study 1 were used for money donation intentions ${ }^{1}$, behavioral support intentions, and identification with the vision. Manipulation check items were similar to those in the first study; a mean of extent of agreement (5-point scale) was calculated for "The proposed E-learning initiative will ..." (1) "support building friendships," (2) "support online collaboration," and (3) "result in more class time being devoted to discussion and interaction."

\footnotetext{
${ }^{1}$ The hypothesis was not supported with this measure so it will not be considered further.
} 
The measure of personal value orientation was revised in an attempt to make it more valid and reliable. Validity (content validity) was sought by revising the format so that it would be possible to use a wider range of pertinent terms for the value domains of autonomy and relatedness. Reliability was sought by using rating scales instead of rankings and by producing a multiple-item scale with items designed to be parallel. Specifically, each of nine items showed terms of opposite content in relation to autonomy and relatedness (e.g., "self-autonomy" with "social connection") at one or the other end of a 6-point scale with anchor terms in mirror image: "describes me much better," "describes me better," and "describes me slightly better" (see Appendix B). Alpha reliability was .88.

\section{Design \& Procedure}

This study was a 2 x 2 between-subjects laboratory experiment. Some weeks before coming to the lab, participants completed the new paired value ranking scale to assess their personal values in terms of autonomy versus relatedness. Students received a credit point toward their psychology course for completing this and various other measures in an hour-long, on-line survey session (in addition to the credit they received for coming to the "lab," a seminar-sized classroom). Then, groups of participants (6-8 per session) were invited to the lab where they viewed one of the two vision presentations as a group. Prior to the presentation, participants were told that the study is about communication impacts. The experimenter then delivered the presentation using a script and aided by computer-projected slides. After the presentation, participants were asked to complete a set of questionnaires which included measures concerning financial support intentions, behavioral support intentions, and a manipulation check. The researcher was absent from the room during the completion of the measures to promote participants' feeling of security about divulging their true reactions to the vision. The study concluded with the experimenter debriefing the participants. 


\section{Results}

\section{Descriptive Statistics}

The low magnitudes of correlations of the various variables in Table 7 with condition indicate that random assignment succeeded in equating conditions. Moreover, given the scoring of the personal value dimension from -2.5 (autonomy-oriented) to 2.5 (relatedness), the mean of .16 (nearly zero) suggests a favorable split. It should also be noted that all 91 participants completed the questionnaires fully, and all data were used.

\section{Multiple Regression Analysis Design}

The absence of any cases of incomplete data and the experimenter's personal observations indicated that a measure of attention did not need to be produced or used in Study 2.

Consequently the MR design was reduced to include the three key variables of condition, personal value, and their two-way interaction. Again, mean centering of measures allowed use of a simultaneous approach to MR analysis.

\section{Manipulation Check}

Firstly, the manipulation check measure was analyzed by MR. In contrast to Study 1 which had required discriminant analysis for detecting a significant difference between conditions in terms of manipulation check items, here a simple mean of the items differed between conditions. The statistically significant regression coefficient for condition in Table 8 corresponds with this mean difference.

Table 8 also shows that the interaction effect in this MR analysis, as depicted in Figure 5, was statistically significant. ${ }^{2}$ Closer inspection revealed that in the E-learning condition the slope $(b=-.141)$ was statistically significant $(t(86)=-2.362), p=, 020)$; this was not the case for the Blended learning condition $(\mathrm{b}=-.019, \mathrm{t}(86)=, p=.801)$. (The reader may need to note that the graphing software placed the legend items in opposite order to what might be expected.) This

\footnotetext{
${ }^{2}$ This interaction effect was not detectible in data from Study 1 . The greater attention among participants or the improved measure of personal values in Study 2 may explain why only Study 2 obtained this effect for this measure.
} 
finding supports the prediction that when cues are present which are discrepant with semantic content (i.e., in the E-learning condition), a "backfire" effect occurs in terms of perception, in which it is as though the person is saying "no that's not so"-but only to the extent that the person's values are consistent with the semantic content. Thus, holding higher value for the explicitly stated ends of a vision may make increase the salience of any discrepancy between the explicit (semantic) message and pertinent perceptual cues.

\section{Value Congruence Hypothesis Tests}

Behavioral support intentions. In the prediction of behavioral support intentions, as seen in Table 9, the interaction of condition $\mathrm{X}$ value orientation yielded statistical significance $(t(87)=2.04, p=.044)$. The pattern of results followed that of the manipulation check. In particular, the slope of the line in Figure 6 for the E-learning condition was statistically significant $(\mathrm{b}=-.163, \mathrm{t}(87)=-2.947, p=.004)$, but this was not so for the Blended learning condition $(\mathrm{b}=-.008, \mathrm{t}(87)=, p=.579)$. These findings suggest that a perceptual backfire was manifested in reduced vision support.

It may also be of interest here to compare the conditions' mean levels of behavioral support for the different kinds of people (value orientations) in the sample. A dichotomous split of the sample was formed along the value orientation continuum, and condition means were compared within each split. There was a statistically significant difference between conditions for relatedness-oriented participants $(t(42)=2.738, p=.009)$, but not for autonomy-oriented participants $(t(45)=0.011, p=.992)$.

Identification. As seen in Table 10, the interaction of condition X value orientation, predicting identification with the vision, approached statistical significance $(p=.111)$. We looked more closely at these marginal results because of the importance of identification findings

in Study 1. In Figure 7, the slope of the line for the E-learning condition again was statistically significant $(\mathrm{b}=.788, t(87)=2.315, p=.023)$, while the slope for Blended learning was not $(\mathrm{b}=-.259, \mathrm{t}(87)=-.781, p=.437)$. And again when looking at the t-tests that compared the condition means within each value orientation split of the sample, there was a statistically 
significant finding for relatedness-oriented participants $(t(42)=2.694, p=.010)$, but not for autonomy-oriented participants $(t(45)=1.065, p=.294)$. One's placing of higher value on the explicitly purported ends of the vision appears not only to increase the salience of discrepancy between perceptual cues and semantics, as indicated by the manipulation check findings, but also to induce rejection of the message in the sense of perceptions of lower meaningfulness and congruence of the vision in relation to the self (i.e., dis-identifying with the vision). This rejection may, of course, be tied to the lower behavioral support among relatedness-oriented participants that was observed with the E-learning vision.

\section{Replication of Mediation Hypotheses Tests with Structural Equation Modeling}

This implied sequence among relatedness-oriented participants, involving relatedness value, then dis-identification, and then reduced behavioral support, was examined more closely in a structural equation model paralleling the SEM produced in Study 1.

The paths estimated in the model are shown in Figure 8 as standardized coefficients. The model evidenced good fit with the data, with $\chi^{2}(32, \mathrm{~N}=91)=24.87, p=.81$. The ratio of $\chi^{2}$ to df was 0.78 , with CFI $=1.0$, and RMSEA $=.00$.

As in Study 1 we defined additional estimands in AMOS to assess and compare the two experimental groups' indirect pathways from social belongingness value to behavioral support intentions. As shown in Table 11, the 95\% upper and lower bounds of the confidence interval of the indirect effects parameters (obtained by bootstrapping) include 0 for the E-Learning condition, but not for the Blended Learning condition. Therefore, in the E-Learning condition, there was a significant indirect effect from social belonging value to behavioral support intentions. More specifically, the social belonging value is negatively associated with identification with the vision, which in turn is positively associated with behavioral support intentions.

\section{Study 2 Discussion}

The basic hypothesis of this study received support. The level of intended behavioral support by participants for a value-congruent vision was higher when perceptual cues about the 
ends of the vision were aligned with the vision's stated ends. Admittedly the manipulation of perceptual cues was accompanied by some bolstering of semantic content, for reasons explained earlier. At a minimum the findings show that the extent of communicated value congruence, at either the "explicit" level of semantic content or the "implicit" level of perceptual cues, matters in support for visions.

Furthermore, the study also provided additional support for the meditational role of identification or dis-identification with a vision (as a function of value congruence with a vision). The corresponding findings from SEM plus the MR findings involving the manipulation check suggested that participants' value orientations carry with them perceptual biases in the sense that nearly the same objective semantic content in a vision presentation does not necessarily yield the same judgment or evaluation for everyone about its objective consequences, depending on nonsemantic cues.

It is also worth noting that there was no inherent antipathy toward a computer-based vision among relatedness-oriented participants after we reduced cue-content discrepancy through production of the Blended Learning condition_-given the absence in this condition of association of any of the outcome measures with the extent of relatedness value orientation. Thus the backfire effect seemed to have occurred because the presentation cues did not support — or even contradicted-the pronounced values.

Although the "backfire" effect was eliminated in this study, a value congruence effect as such was not obtained. In relation to Figure 6, for example, such an effect would exist if the solid line for relatedness-oriented individuals rose well above that of the autonomy-oriented individuals for the blended-learning condition (to the right). This observation suggests that in order to generate distinctively high support among relatedness-oriented individuals for a computer-involving vision of enhanced education, still greater efforts must be made to communicate the vision's social benefits and, perhaps, additional socially-oriented elements must, in fact, be built into the vision. 


\section{General Discussion}

An overarching question prompted this research: When a vision is congruent with some audience members' personal values yet incongruent for others' values, what are some of the complications that arise? Previous research, which had supported the theorized role of personal values in the motivational impact of visions, was restricted to contexts where value congruence was likely to be highly dominant (e.g., Shipley \& Michela, 2006). However, potential incongruence along with congruence may be what leaders often confront when formulating and presenting visions. Thus for the present research, visions were designed to have elements that were both congruent and incongruent with audience members' personal values.

\section{Perception Precedes Motivation}

Complications did indeed arise when we attempted to detect effects of congruence and incongruence by emphasizing one or the other set of elements of a vision. The primary complication revolves around how people perceive visions. The presentation of a vision engages not only motivational mechanisms, but also perceptual processes. Semantic content within a vision conveys meaning, as do images and other stimuli and elements of form. These "cues" may instill meanings which may or may not be consistent with those that are semantically expressed. When some of the findings of Study 1 ran opposite to prediction of congruent response, Study 2 was designed to determine whether this kind of inconsistency between explicit message and implicit cueing could explain those findings. Results of Study 2 supported this analysis of the earlier, unexpected findings — an analysis that was grounded also in psychological and marketing literature as sketched in the discussion for Study 1.

\section{Dis-identification Prompts Rejection}

When, in both studies, participants with high personal value on relatedness were seen to reject the vision that had been intended to be value congruent for them, we tested our prediction of a role for vision identification - but with a twist. We reasoned that vision rejection could be fueled by dis-identification, and tests of corresponding indirect effects confirmed this reasoning. The findings indicated that once value incongruence was perceived, dis-identification occurred 
(as indicated, for example, by disagreeing with statements concerning similarity of one's ideals and the ideals intrinsic to the vision, and concerning whether the organization's pursuit of the vision would be a source of personal pride). Dis-identification, in turn, mediated part of the effect of value-incongruence upon intentions to engage in behavior that would promote the vision.

These findings support our proposed expansion of theory concerning the operation of personal values in motivation through visions. By definition, values are connected with various categories of ends or means. Potentially, the motivational impact of visions could be only a reflection of subjectivity expected utility (S.E.U.) or related reward-expectation-based motivational processes — connected with those ends or means. Specifically, with value congruence, the vision offers an opportunity to pursue valued ends. Our theoretical analysis contrasted this utility-based explanation with an identity-based one. Because a strongly held value becomes part of the self-concept, support of a vision could be an identity-maintaining or identity-enhancing activity. The findings involving dis-identification as a mediator imply such a role for identity in motivation as induced by visions.

\section{Congruence, Incongruence, and Non-congruence}

In another respect, some other findings could have been somewhat different from what they were. The form of the interaction effects obtained in Study 1 generally was that of a "crossover." For example, in Figures 1 and 2, it appears there is not only rising donation intention with higher personal value congruent with the autonomy condition, but also falling donation intention with higher levels of the same value (self-direction) in the other, relatedness condition. Neither of these directional trends held its own statistical significance, and although this result could be a matter of statistical power (i.e. N, given the amount of variance explained), it could also signal that the obtained interaction was, in fact, a joint product of tendencies in both directions. The salient alternative result would have been for there to be no difference in donation intention as a function of the autonomy value in the relatedness condition - that is, non-congruence, as opposed to incongruence. 
This pattern of findings may offer insight into how personal values of relatedness and autonomy relate to one another within the domain of visions. It suggests they have the opposing nature implied by the partly opposing positions they occupy on Schwartz 's (1992) values circumplex (i.e., people who favor one tend not to favor the other). ${ }^{3}$

We used the apparent opposition of autonomy and relatedness to produce a personal value measure in Study 2 that had much better properties (e.g., alpha of .88) than the measures in Study 1 . With the new measure, Study 2 replicated a key finding from the earlier one - the statistically significant, negative association of relatedness value to behavioral support of the vision in the original relatedness condition (the condition with computer-related cues, intended to make pro-relatedness consequences prominent). Although not at all definitive, this replication with this measure suggests that the corresponding value structure in this context is, indeed, bipolar or oppositional. (The replication also suggests that the less desirable measure in Study 1 was, nevertheless, good enough.)

Next we will comment on the instances in which a congruence effect (statistical interaction), involving autonomy, could have been obtained but was not obtained in Study 1 . The measurement limitations already discussed could be a sufficient explanation. However, the difficulty of getting people enthused about a change to their way of working, whether schoolwork or other work, should also be considered. As we have noted, previous supportive experimental research on value-based motivation (Shipley and Michela, 2006) used highly valuecongruent visions promoting expanded bicycle paths, light rail transit, and so forth, with research participants likely overall to hold highly congruent values. However, the envisioned change in the present study was, at root, less- upliftingly and less-universally-valued, toward (a) more use of computers to obtain course content and (b) more use of time in class meetings for interaction

\footnotetext{
${ }^{3}$ It is of interest that the literature on independent and interdependent self-construal can be read as pointing also to opposition, not orthogonality of the constructs-although this is not the only way to read this literature. The basic culture distinction, with Eastern as more interdependent and Western as more independent, points this way. So does the study cited in the discussion of Study 1 , in which advertisements directed at the U.S. middle class signal independence, while those to the working class cue interdependence.
} 
with peers and faculty. Besides values of autonomy and relatedness, other factors in the response to the vision could include intrinsic interest in learning, or perceptions of the likely consequences of the change for one's performance in course work, among many others. In other words, some people might not care one way or the other, and some people who are value congruent may have had other reasons for opposition. These inherent difficulties in this context may also explain the relatively low amount of variance explained and the lack of statistically significant "simple effects" when evidence of an omnibus effect of congruence was obtained.

Thus the use of these particular visions in this context was a double-edged sword. On one side, findings in support of congruence were not all that they might have been. On the other, obtaining some such findings was an accomplishment because of the difficulties noted, and, consequently, we conclude that value congruence does matter. We would advise future researchers to err on the side of exuberance and pithiness when developing work-related visions

for their studies. In this connection it is of interest that stronger effects (in terms of percentage of explained variance and obtaining simple effects within conditions) were seen in instances of vision rejection (the backfire) as compared with promotion (autonomy congruence findings). Thus, people appeared to get more worked up against a vision they viewed as false (with falseness indicated by manipulation check findings in Study 2), and contrary to their identities, as compared with their responses to a vision presumably viewed as congruent, true, and identitysupportive ("presumably" because direct evidence of this view was not available from Study 1).

\section{Implications for Leaders}

The authors recognize that students' work and students' work contexts are not identical to other work and contexts, and that behavioral intention for money donation or action does not assure follow-up in actual behavior. Still, by supposing that some amount of connection exists across these domains, we can offer the following implications for leaders of businesses and notfor-profit organizations.

Attend to "cues" in vision presentations. When receiving communications, people acquire meaning not only from words or other semantic conveyance, but also from symbols, 
images, and other non-verbal information. Study 2 specifically indicates that altering the nonverbal information alters the total meaning and thus response to a communication. Evidence for this conclusion is, admittedly, compromised somewhat by having bolstered the verbal or semantic information about relatedness consequences in the "Blended learning" (cue-consistent) condition as compared with the "E-learning" (cue-inconsistent) condition. However we do not agree that this evidence is completely compromised, because our analysis of the reason for the backfire effect appears to have been correct: In the initial version of the relatedness-promoting vision, relatedness-oriented people did not perceive enough relatedness-promoting emphasis to support it and, indeed, they rejected it. Our multi-faceted bolstering of relatedness consequences in the Blended learning condition resembles studies cited in the Introduction in which value prominence was one of several aspects of visionary presentation (e.g., Kirkpatrick and Locke, 1996). Just as the present study has more narrowly focused on value congruence, future research can zero in on perceptual cues in this regard.

In any event, as vision researchers we were surprised to see the backfire effect in the first study (although glad to have replicated it in the second, showing that it was not a statistical fluke). Evidently leaders cannot rely on favorable effects from apparently "logical" congruence of their visions with the values of their followers. They should scrutinize the message itself for any inconsistent content—semantic or symbolic (images, framing as in title, etc.)—or for deficient content (e.g., not enough detail of how valued ends will be realized).

Political leaders accomplish this scrutiny through extensive polling and use of focus groups. Should organizational leaders do the same thing? Perhaps yes and no. "Yes" to the extent that vision presentations leave room for interpretation, and to the extent that by gauging how the vision is understood, its presentation can be revised to ensure that people interpret it as intended. "No" to the extent that a vision could be tailored to be what people want to hear but not be an accurate picture of the future state that will promote the interests of the organization and its members. As indicated in the Introduction, a vision should give direction to employees, helping them, for example, to navigate otherwise conflicting priorities. Thus the vision should be an 
accurate or realistic one in this sense of being directive and energizing in relation to strategic needs and priorities of the organization.

Something for everyone? An unanswered question from our study is whether a vision presentation should describe how multiple valued ends would be promoted by pursuing a vision. Our study only compared alternative emphases. We suspect that the answer to the specific question here depends on the particular values of the audience and other aspects of the context. Based on this study's findings, it appears that in the context of a vision of potentially greater use of computers and altered use of class time in university education, there may be a bias by some members of the audience to perceive incompatibility between promotion of autonomy and of relatedness (because of the "opposition" of these values as discussed earlier). In other contexts, however, attempts to offer "something for everyone" may be more universally motivating.

Juice it up. After experiencing difficulty in detecting an effect of congruence in this experimental context - where we had the seeming advantage to be able to select the pertinent value dimensions and messages — we were reminded of the Herculean task given to leaders when they seek to influence followers through visions. Visions should not be expected to act alone in influencing followers; they should be aligned with other organizational systems, structures, and processes (Collins and Porras, 2000; Michela, 2012). Moreover, in addition to the content and symbolism in visions as already discussed, both of which should be as energizing as possible, the presentation by the leader should be enthusiastic and confident (see Antonakis, Fenley, \& Liechti, 2012). In these regards the organizational leader has a potential advantage over experimenters who seek impact through visions, because in experimental studies (including this one) visions are, by design, the only element of influence, distinct from presentation style or "charisma."

"Yes we can." Having discussed utility and identity as possible sources of motivation to pursue visions, finally we note that many other established motivational principles are likely to apply to motivational impacts of organizational visions, and these principles should be considered when formulating and communicating visions. For formulation, experimental 
research by Hideg, Michela, and Ferris (2011) supports the position in Collins and Porras (2000) that collaborative or participative formulation of visionary policies is best for motivation. Specifically, using measures similar to those of the present study, Hideg et al. (2011) demonstrated greater buy-in to a visionary organizational policy when participants had "instrumental" voice versus non-instrumental voice.

In the 2008 U.S. presidential election campaign, Barack Obama was seen as charismatic when he pronounced "yes we can." Notably, "yes he did" knock out the initial front-runner, Hillary Clinton, from the Democratic candidacy for the presidency. The present point is simply that within a vision, other well-established motivational factors, such as self-efficacy (Bandura, 1986), also should be marshaled to maximize impact. At the same time, "spinning" a vision seems unlikely to have much impact. Thus, our study's findings of effects of value congruence and perceived incongruence of personal values indicate that the true content of a vision matters for whether congruence or incongruence will be perceived and consequential. Phony visions will not suffice. 


\section{References}

Abbott, G. N., White, F. A., \& Charles, M. A. (2005). Linking values and organizational commitment: A correlational and experimental investigation in two organizations. Journal of Occupational and Organizational Psychology, 78, 531-551.

Ajzen, I. (1991). The theory of planned behavior. Organizational Behavior and Human Decision Processes, 50, 179-211.

Alderfer, C.P. (1969). An empirical test of a new theory of human needs. Organizational Behavior and Human Performance, 4, 142-175.

Antonakis, J., Fenley, M., \& Liechti, S. (2012). Learning charisma: Transforming yourself into the person others want to follow. Harvard Business Review, June, 127-130.

Arbuckle, J.L. (1989). AMOS: Analysis of moment structures. The American Statistician, 43, 66.

Arthuaud-Day, M.L., Rode, J.C., \& Turnley, W.H. (2012). Direct and contextual effects of individual values on organizational citizenship behavior in teams. Journal of Applied Psychology, 97, 792-807.

Ashforth, B. E. \& Mael, F. (1989). Social identity theory and the organization. Academy of Management Review, 14, 20-39.

Ashforth, B. E., Harrison, S. H., Corley, K. G. (2008). Identification in organizations: An Examination of Four Fundamental Questions. Journal of Management, 34, 325-374.

Awamleh, R. \& Gardner, W. L. (1999). Perceptions of leader charisma and effectiveness: The effects of vision content, delivery, and organizational performance. Leadership Quarterly, 10, 345-373.

Baum, J. R., \& Locke, E. A. (2004). The relationship of entrepreneurial traits, skill, and motivation to subsequent venture growth. Journal of Applied Psychology, 89, 587-598.

Baum, J. R., Locke, E. A., \& Kirkpatrick, S. (1998). A longitudinal study of the relation of vision and vision communication to venture growth in entrepreneurial firms. Journal of Applied Psychology, 83, 43-54. 
Bouckenooghe, D. (2005). The prediction of stress by values and value conflict. The Journal of Psychology: Interdisciplinary and Applied, 139, 369-382.

Cable, D. M., \& Judge, T. A. (1996). Person-organization fit, job choice decisions, and organizational entry. Organizational Behavior and Human Decision Processes, 67, 294311.

Cascio, W. F. (1995). Whither industrial and organizational psychology in changing nature of economic. American Psychologist, 50, 928-939.

Choi, J.N. (2007). Change-oriented organizational citizenship behavior: Effects of work environment characteristics and intervening psychological processes. Journal of Organizational Behavior, 28, 467-484.

Collins, J.C. \& Porras, J.I. (2000). Built to last: Successful habits of visionary companies. London: Random House.

Conger, J. A. (1989). The Charismatic Leader. San Francisco: Jossey-Bass.

Conger, J. A., \& Kanungo, R. N. (1998). Charismatic Leadership in Organizations. Thousand Oaks, CA: Sage Publications.

Daly, J. P., \& Pouder, R. W. (2004). The effects of initial differences in firms' espoused values on their postmerger performance. The Journal of Applied Behavioral Science, 40.

Deci, E. \& Ryan, R. (Eds.) (2002). Handbook of self-determination research. University of Rochester Press.

Dutton, J. E., Dukerich, J. J., \& Harquail, C. V. (1994). Organizational images and member identification. Administrative Science Quarterly, 39, 239-263.

Dvir, T., Kass, N., \& Shamir, B. (2004). The emotional bond: Vision and organizational commitment among high-tech employees. Journal of Organizational Change Management, 17, 126-43.

Feiler, D.C., Tost, L.P., \& Grant, A.M. (in press). Mixed reasons, missed givings: The costs of blending egoistic and altruistic reasons in donation requests. Journal of Experimental Social Psychology. 
Frese, M., Beimel, S., \& Schoenborn, S. (2003). Action training for charismatic leadership: Two evaluations of studies of a commercial training module on inspirational communication of a vision. Personnel Psychology, 56, 671-697.

Goodman, S. A., \& Svyantek, D. J. (1999). Person-organization fit and contextual performance: Do shared values matter. Journal of Vocational Behavior, 55, 254-275.

Gruenfeld, D.H., Mannix, E.A., Williams, K.Y., \& Neale, M.A. (1996). Group composition and decision making: How member familiarity and information distribution affect process and performance. Organizational Behavior and Human Decision Processes, 67, 1-15.

Hackman, J.R. \& Oldham, G.R. (1980). Job Redesign. Reading, MA: Addison-Wesley.

Hauser, M. \& House, R. J. (2000). Lead through vision and values. In E. A. Locke (Ed.), The Blackwell Handbook of Organizational Behavior (pp. 257-273). Malden, MA: Blackwell Publishers Inc.

Herscovitch, L., \& Meyer, J. P. (2002). Commitment to Organizational Change: Extension of a Three-Component Model. Journal of Applied Psychology, 87, 474-487.

Hideg, I., Michela, J. L., \& Ferris, D. L. (2011). Overcoming negative reactions ofnonbeneficiaries to employment equity: The effect of participation in policy formulation. Journal of Applied Psychology, 96(2), 363-376.

Hitlin S. (2003). Values as the core of personal identity: drawing links between two theories of the self. Social Psychology Quarterly, 66, 118-137.

Hitlin, S., \& Piliavin, J. A. (2004). Values: reviving a dormant concept. Annual Review of Sociology, 30, 359-393.

Holladay, S.J. \& Coombs, W.T. (1994). Speaking of visions and visions being spoken: An exploration of the effects of content and delivery on perceptions of leader charisma. Management Communication Quarterly, 8, 165-189.

Kirkpatrick, S. A., \& Locke, E. A. (1996). Direct and indirect effects of three core charismatic leadership components on performance and attitudes. Journal of Applied Psychology, 81, $36-51$. 
Kotter, J. P. (1990). A Force for Change: How Leadership Differs from Management. New York: Free Press.

Kouzes, J. M., \& Posner, B. Z. (1987). The Leadership Challenge. San Francisco: Jossey-Bass.

Kristof-brown, A. L., Zimmerman, R. D., \& Johnson, E. C. (2005). Consequences of individuals' fit at work: A meta-analysis of person-job, person-organization, person-group, and person-supervisor fit. Personnel Psychology, 58, 281-342.

Updegraff, J. A., Sherman, D. K., Luyster, F. S., \& Mann, T. L. (2007). The effects of message quality and congruency on perceptions of tailored health communications. Journal of Experimental Social Psychology, 43, 248-256.

Mael, F. A., \& Tetrick, L. E. (1992). Identifying organizational identification. Educational and Psychological Measurement, 52, 813-824.

Markus, H. R., \& Kitayama, S. (2003). Models of agency: Sociocultural diversity in the construction of action. In V. Murphy-Berman \& J. Berman (Eds.), Nebraska Symposium on Motivation: Vol. 49. Crosscultural differences in perspectives on self (pp. 1-57). Lincoln: University of Nebraska Press.

Markus, H.R. \& Kitayama, S. (1991). Culture and the self: Implications for cognition, emotion, and motivation. Psychological Review, 98, 224-253.

Michela, J.L. (2012). How to sell your start-up's long term vision. Retrieved August 24, 2000, from Entrepreneur.com's Web site: http://www.entrepreneur.com/blog/223797.

Pratt, M. G. (1998). To be or not to be: Central questions in organizational identification. In D. A. Whetten \& P. C. Godfrey (Eds.), Identity in Organizations (pp. 171-207). Thousand Oaks, CA: Sage.

Raghubir, P. \& Celly, K.S. (2011). Promoting promotions: Does showcasing free gifts backfire? Journal of Business Research, 64, 55-58.

Ratner, R. K. \& Miller, D. T. (2001). The norm of self-interest and its effects on social action. Journal of Personality and Social Psychology, 81(1), 5-16.

Rokeach, M. (1973). The nature of human values. New York: The Free Press. 
Schwartz, S. H. (1992). Universals in the content and structure of values: Theoretical advances and empirical tests in 20 countries. Advances in Experimental Social Psychology, 25, 165.

Schwartz, S. H. (1994). Are there universal aspects in the structure and contents of human values? Journal of Social Issues, 50, 19-45.

Schwartz, S. H. (1999). A theory of cultural values and some implications for work. Applied Psychology: An International Review, 48, 23-47.

Schwartz, S. H. \& Bilsky, W. (1987). Toward a universal psychological structure of human values. Journal of Personality and Social Psychology, 53, 550-562.

Shamir, B. (1991). Meaning, self and motivation in organizations. Organizational Studies, 12, 405-424.

Shamir, B., Arthur, M. B., \& House, R. J. (1994). The rhetoric of charismatic leadership: a theoretical extension, a case study, and implications for future research. Leadership Quarterly, 5, 25-42.

Shipley, R., \& Michela, J. L. (2006). Can vision motivate planning action? Planning, Practice \& Research, 21, 223-244.

Stephens, N.M., Markus, H.R., \& Townsend, S.S.M. (2007). Choice as an act of meaning: The case of social class. Journal of Personality and Social Psychology, 93, 814-830.

Tajfel, H. \& Turner, J.C. (1979). The social identity theory of intergroup behavior. In W.G. Austin \& S. Worchel (Eds.), The social psychology of intergroup relations. Chicago, IL: Nelson-Hall.

Van Dick, R., Wagner, U., Stellmacher, J., \& Christ, O. (2004). The utility of a broader conceptualization of organizational identification: Which aspects really matter? Journal of Occupational and Organizational Psychology, 77, 171-191.

Verplanken, B., \& Holland, R. (2002). Motivated decision making: Effects of activation and selfcentrality of values on choices and behavior. Journal of Personality and Social Psychology, 82, 434-447. 
Zaccaro, S. J. (2001). The Nature of Executive Leadership: A Conceptual and Empirical Analysis of Success. Washington, DC: APA Books.

Zaccaro, S. J., \& Banks, D.J. (2001). Leadership, vision, and organizational effectiveness. In S. J. Zaccaro \& R. J. Klimoski (Eds.), The nature of organizational leadership (pp. 181218). San Francisco: Jossey-Bass.

Zaccaro, S. J., \& Banks, D. (2004). Leader visioning and adaptability: Bridging the gap between research and practice on developing the ability to manage change. Human Resource Management, 43, 367-380.

Zhang, Y.\& Gelb, B.D. (1996). Matching advertising appeals to culture: The influence of products' use condition. Journal of Advertising, 25(3), 29-46. 
Table 1

Means, Standard Deviations, and Intercorrelations

\begin{tabular}{|c|c|c|c|c|c|c|c|c|c|c|c|}
\hline Variable & Mean & $\mathrm{SD}$ & 1 & 2 & 3 & 4 & 5 & 6 & 7 & 8 & 9 \\
\hline 1. Condition & 0.35 & 0.48 & 1.00 & & & & & & & & \\
\hline 2. Self-Direction Value & 4.55 & 2.09 & -.03 & 1.00 & & & & & & & \\
\hline 3. Autonomy Value & 4.53 & 2.19 & .10 & -.11 & 1.00 & & & & & & \\
\hline 4. Social-Connection Value & 5.63 & 1.94 & -.01 & -.13 & -.15 & 1.00 & & & & & \\
\hline 5. Belonging Value & 3.87 & 2.03 & -.03 & -.01 & $-.26 * *$ & .07 & 1.00 & & & & \\
\hline 6. Money donation intent & 0.19 & 0.39 & -.07 & -.06 & -.04 & -.05 & .05 & 1.00 & & & \\
\hline 7. Money donation amount & 10.26 & 34.49 & .08 & -.06 & -.05 & .05 & .05 & $.62 * *$ & 1.00 & & \\
\hline 8. Behavioral support intentions & 3.01 & 2.29 & 0.06 & -.05 & -.05 & -.14 & -.13 & $.22 * *$ & $.24 * *$ & 1.00 & \\
\hline 9. Identification with vision & 3.83 & 1.16 & -0.01 & .00 & -.07 & -.08 & -.01 & $.25 * *$ & $.17 *$ & $.61 * *$ & 1.00 \\
\hline
\end{tabular}

$* \mathrm{p}<0.05 . * * \mathrm{p}<0.01$ 
Table 2

Standardized Canonical Discriminant Function Coefficients

\begin{tabular}{lc}
\hline \multicolumn{1}{c}{ Item } & Weight \\
\hline The online learning programs utilize self-set goals & -.57 \\
The proposed E-Learning programs will support online collaboration & .29 \\
The proposed E-Learning programs will support autonomous learning & -.38 \\
The proposed E-Learning initiative will result in more class time being devoted to & .74 \\
discussion and interaction & \\
\hline
\end{tabular}


Table 3

Standardized and Unstandardized Regression Coefficients for Regression Analysis of Self-Direction Value X Condition on Money Donation

\begin{tabular}{lcccc}
\hline \multicolumn{1}{c}{ Variable } & $B$ & $S E B$ & $\beta$ & Prob. \\
\hline [Constant] & .738 & .138 & .40 & .000 \\
Self-Direction Value & -.027 & .070 & -.03 & .701 \\
Condition & -.192 & .290 & -.05 & .508 \\
Attention & -.005 & .142 & .00 & .969 \\
Self-Direction Value X Condition & -.252 & .148 & -.14 & .091 \\
Self-Direction Value X Attention & .146 & .075 & .17 & .052 \\
Condition X Attention & & & & .905 \\
Self-Direction Value X Condition X & .043 & .142 & .03 & .764 \\
Attention & & & & \\
\hline
\end{tabular}

Note: The simultaneous regression with all seven predictors yielded $\mathrm{R}^{2}=.042, \mathrm{~F}(7,155)=.924$, $p=0.490$. 
Table 4

Standardized and Unstandardized Regression Coefficients for Regression Analysis of Social Belonging Value X Condition on Behavioral Support Intentions

\begin{tabular}{|c|c|c|c|c|}
\hline Variable & $B$ & $S E B$ & $\beta$ & Prob. \\
\hline [Constant] & 2.943 & .175 & .78 & .000 \\
\hline Social Belonging Value & -.200 & .091 & -.11 & 029 \\
\hline Condition & .290 & .370 & .04 & .435 \\
\hline Attention & .294 & .188 & .08 & .120 \\
\hline Social Belonging Value X Condition & -.415 & .204 & -.10 & .044 \\
\hline Social Belonging Value X Attention & -.111 & .091 & -.06 & .226 \\
\hline Condition X Attention & -.383 & .352 & -.05 & .278 \\
\hline Social Belonging Value X Condition & .338 & .185 & .10 & .071 \\
\hline $\mathrm{X}$ Attention & & & & \\
\hline
\end{tabular}

Note: The simultaneous regression with all seven predictors yielded $\mathrm{R}^{2}=.110, \mathrm{~F}(7,162)$ $=2.729, p=0.011$. 
Table 5

A Comparison of the Three Versions of the Structural Equation Model

\begin{tabular}{lccccc}
\hline & $\chi^{2}$ & df & $p$ & $\Delta \chi^{2}$ & $\Delta$ df \\
\hline $\begin{array}{l}\text { Version 1: } \\
\text { Model with all } \\
\text { paths fixed }\end{array}$ & 46.91 & 33 & .06 & & \\
$\begin{array}{l}\text { Version 2: } \\
\begin{array}{l}\text { Model with 1 } \\
\text { free path }\end{array}\end{array}$ & 41.05 & 32 & .13 & $46.91-41.05$ & 1 \\
$\begin{array}{l}\text { Version 3: } \\
\text { Model with all } \\
\text { free paths }\end{array}$ & 40.58 & 30 & .09 & $41.05-40.58$ & 2 \\
\hline
\end{tabular}


Table 6

Confidence Intervals of the Standardized Indirect Effects of Relatedness Values on Behavioral Support Intentions for the Two Experimental Conditions

\begin{tabular}{lcc}
\hline & $95 \%$ Lower Bound & $95 \%$ Upper Bound \\
\hline Autonomy Condition & -.052 & .277 \\
Relatedness Condition & -.381 & -.001 \\
\hline
\end{tabular}


Table 7

Descriptive Statistics for Selected Study 2 Variables, Split by Condition

\begin{tabular}{|c|c|c|c|c|c|c|c|c|}
\hline \multirow[b]{2}{*}{ Variable } & \multicolumn{4}{|c|}{ E-Learning } & \multicolumn{4}{|c|}{ Blended Learning } \\
\hline & Mean & S.D. & Min & $\operatorname{Max}$ & Mean & S.D. & Min & $\operatorname{Max}$ \\
\hline Value Orientation $^{\mathrm{a}}$ & .16 & 1.05 & -1.61 & 2.50 & .16 & 1.09 & -2.50 & 1.83 \\
\hline Value Orientation X & .08 & .52 & -1.25 & .81 & .08 & .54 & -1.25 & .92 \\
\hline Condition $^{\mathrm{b}}$ & & & & & & & & \\
\hline
\end{tabular}

Note. The condition variable's mean across the two conditions was .52, given the 44 participants in the E-learning condition and the 47 in the Blended learning condition.

${ }^{\mathrm{a}}>0=$ High Social, $<0=$ Low Social. E-Learning: High Social, $\mathrm{n}=30$. Low Social, $\mathrm{n}=14$. Blended Learning: High Social, $\mathrm{n}=31$; Low Social, $\mathrm{n}=16$.

${ }^{\mathrm{b}}>0=$ Good Value Orientation \& Condition Fit, $<0=$ Poor Value Orientation \& Condition Fit. 
Table 8

Standardized and Unstandardized Regression Coefficients for Regression Analysis of Manipulation Check

\begin{tabular}{lcccr}
\hline \multicolumn{1}{c}{ Variable } & $B$ & SE B & $\beta$ & Prob. \\
\hline [Constant $]$ & .016 & .096 & & .000 \\
Value Orientation & -.128 & .091 & -.14 & .200 \\
Vision Condition & .637 & .193 & .32 & .001 \\
Orientation X Condition & .505 & .182 & .27 & .011 \\
(Congruence) & & & & \\
\hline
\end{tabular}

Note: The simultaneous regression with all three predictors yielded $\mathrm{R}^{2}=.163, \mathrm{~F}(3,89)=5.584$, $p=0.002$. 
Table 9

Standardized and Unstandardized Regression Coefficients for Regression Analysis of Behavioral Support for the Vision

\begin{tabular}{lrrrr}
\hline \multicolumn{1}{c}{ Variable } & $B$ & SE B & $\beta$ & Prob. \\
\hline [Constant $]$ & .481 & .029 & & .000 \\
Value Orientation & -.053 & .027 & -.20 & .056 \\
Vision Condition & .105 & .058 & .18 & .071 \\
Orientation X Condition & .111 & .054 & .21 & .044 \\
(Congruence) & & & & \\
\hline
\end{tabular}

Note: The simultaneous regression with all seven predictors yielded $\mathrm{R}^{2}=.102, \mathrm{~F}(3,90)=3.280$, $p=0.025$. 
Table 10

Standardized and Unstandardized Regression Coefficients for Regression Analysis of Identification with Vision

\begin{tabular}{lcccr}
\hline \multicolumn{1}{l}{ Variable } & $B$ & SE B & $\beta$ & Prob. \\
\hline [Constant] & 3.848 & .120 & & .000 \\
Value Orientation & -.088 & .113 & -.08 & .442 \\
Vision Condition & .673 & .240 & .28 & .006 \\
& & & & .111 \\
Orientation X Condition & .366 & .227 & .16 & .111 \\
(Congruence) & & & & \\
\hline
\end{tabular}

Note: The simultaneous regression with all seven predictors yielded $\mathrm{R}^{2}=.143, \mathrm{~F}(3,90)=4.829$, $p=0.004$. 
Table 11

Confidence Intervals of the Standardized Indirect Effects of Relatedness Values on Behavioral Support Intentions for the Two Experimental Conditions

\begin{tabular}{lcc}
\hline & $95 \%$ Lower Bound & $95 \%$ Upper Bound \\
\hline E-Learning Condition & -.2 .14 & -.202 \\
Blended Learning Condition & -.1 .099 & 1.388 \\
\hline
\end{tabular}




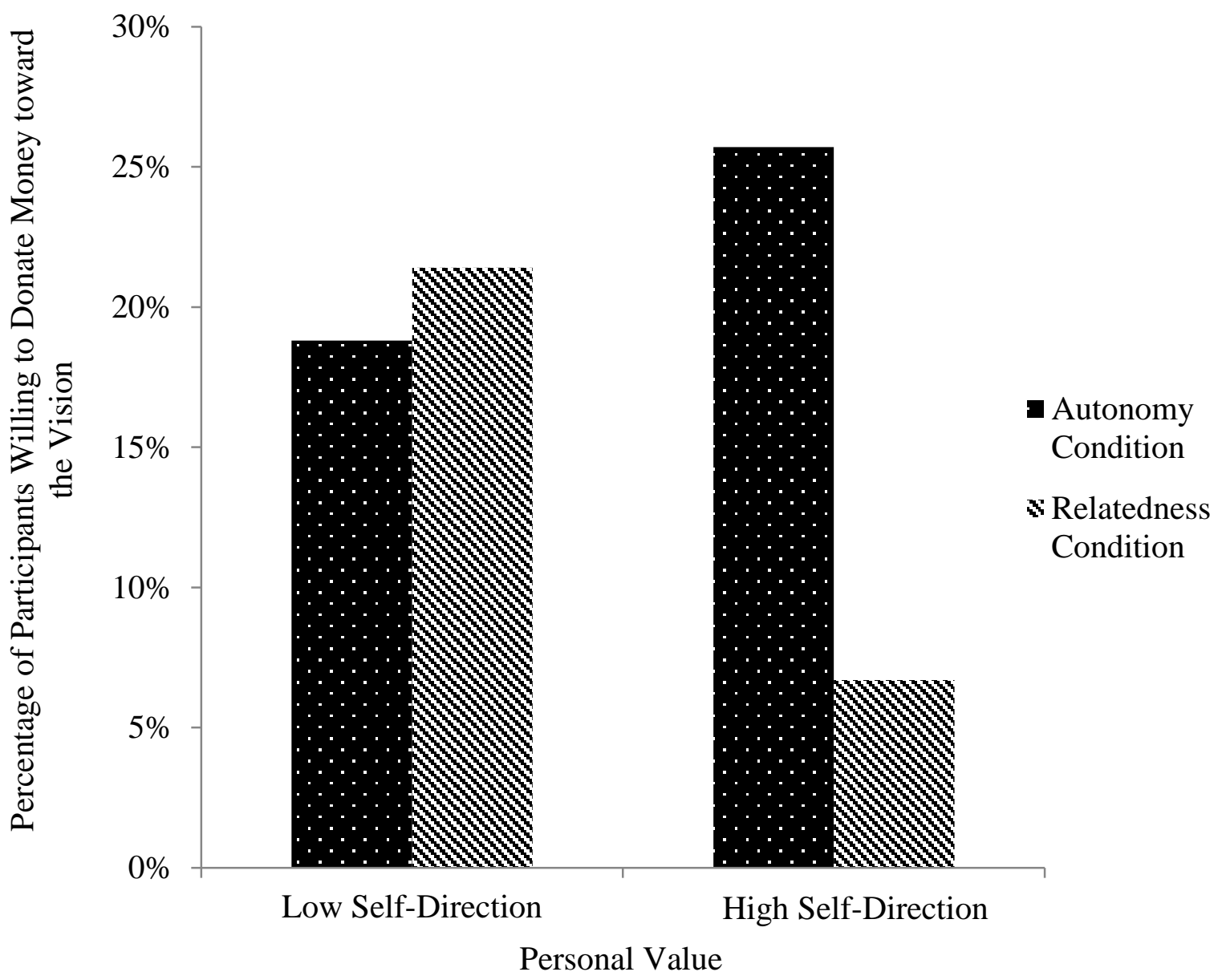

Figure 1. Interaction of self-direction value $\mathrm{X}$ condition for money donation intent (yes/no). 


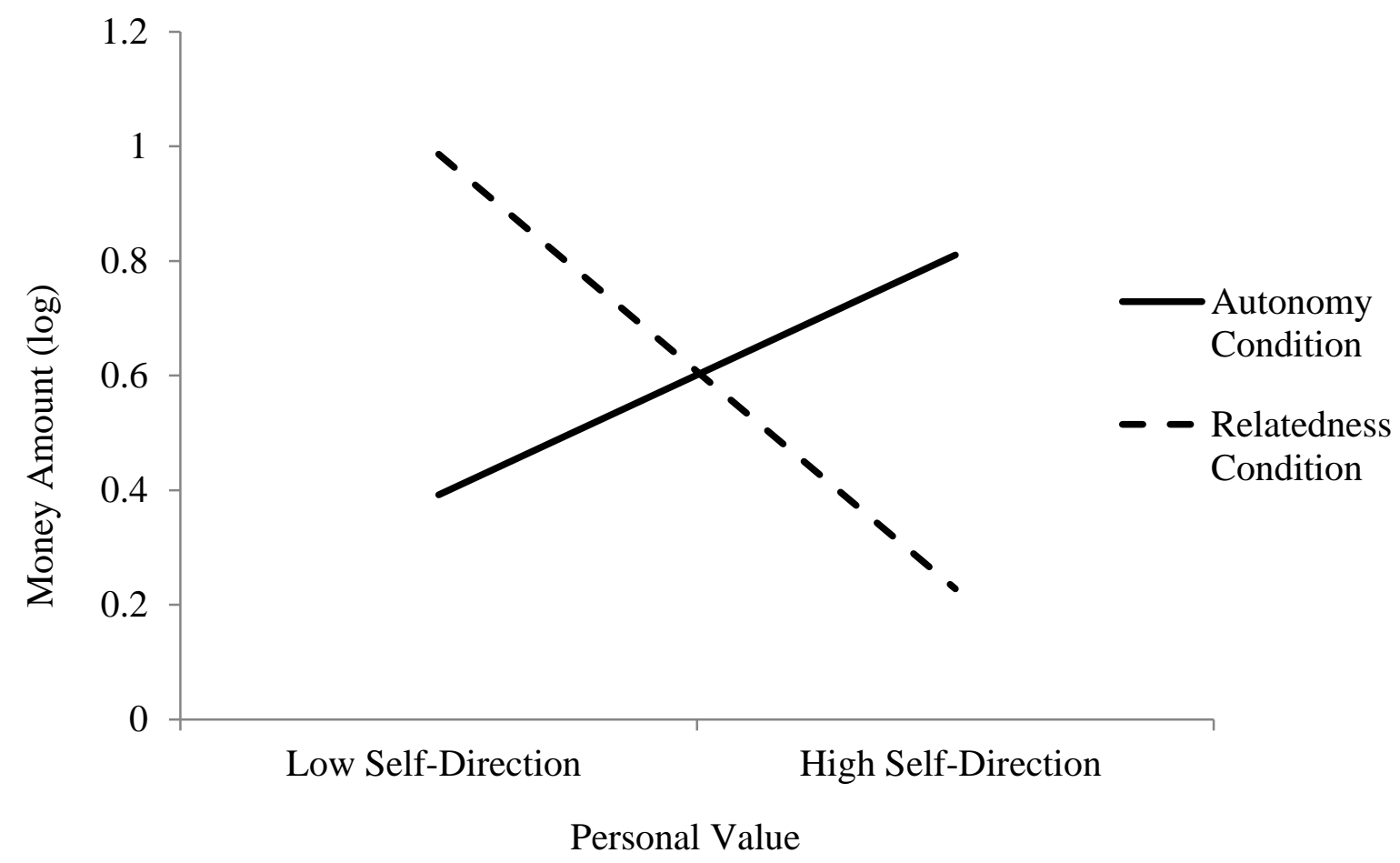

Figure 2: Interaction of self-direction value $\mathrm{X}$ condition for money donation amount (log). 


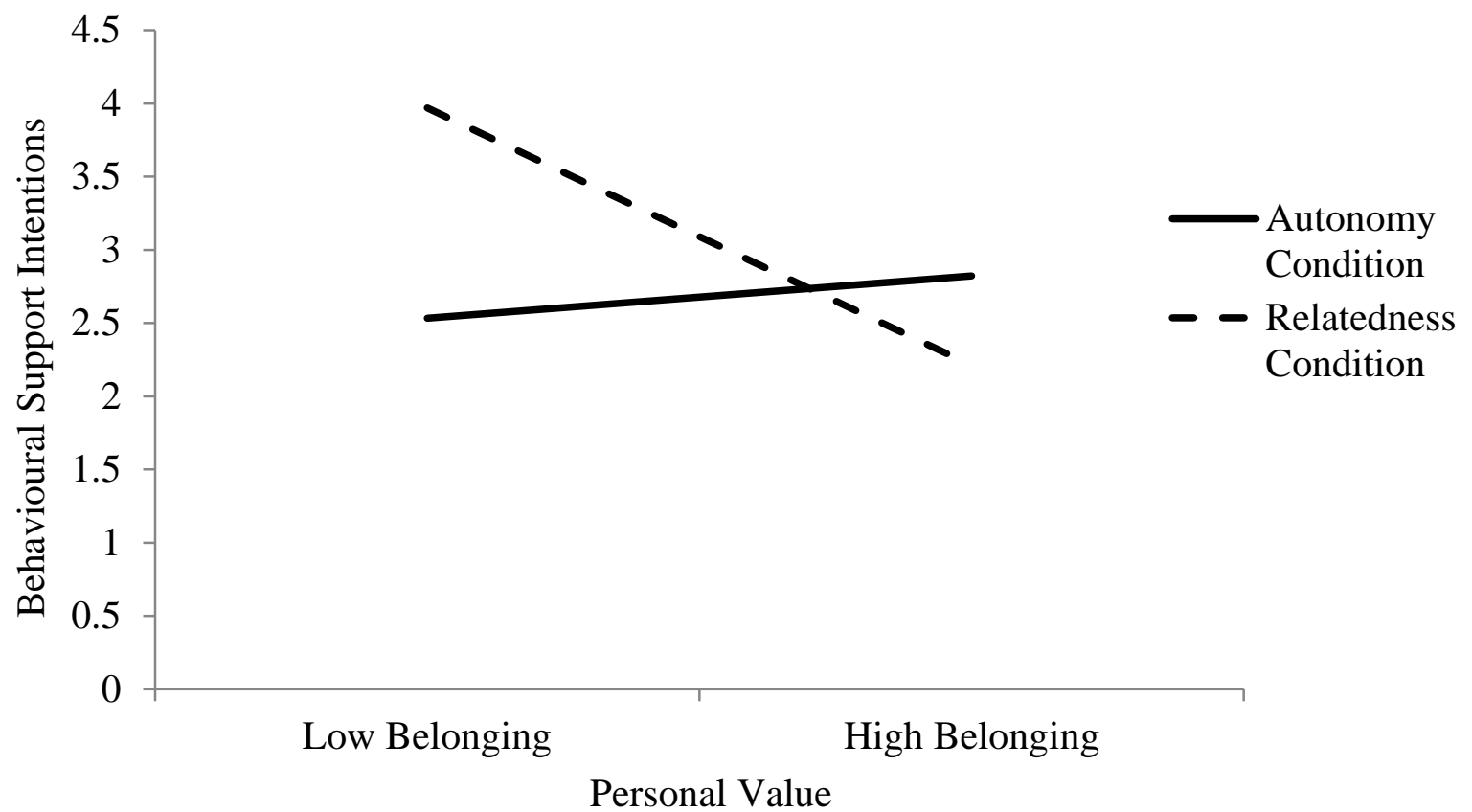

Figure 3. Interaction of belonging value $\mathrm{X}$ condition for behavioral support intentions. 


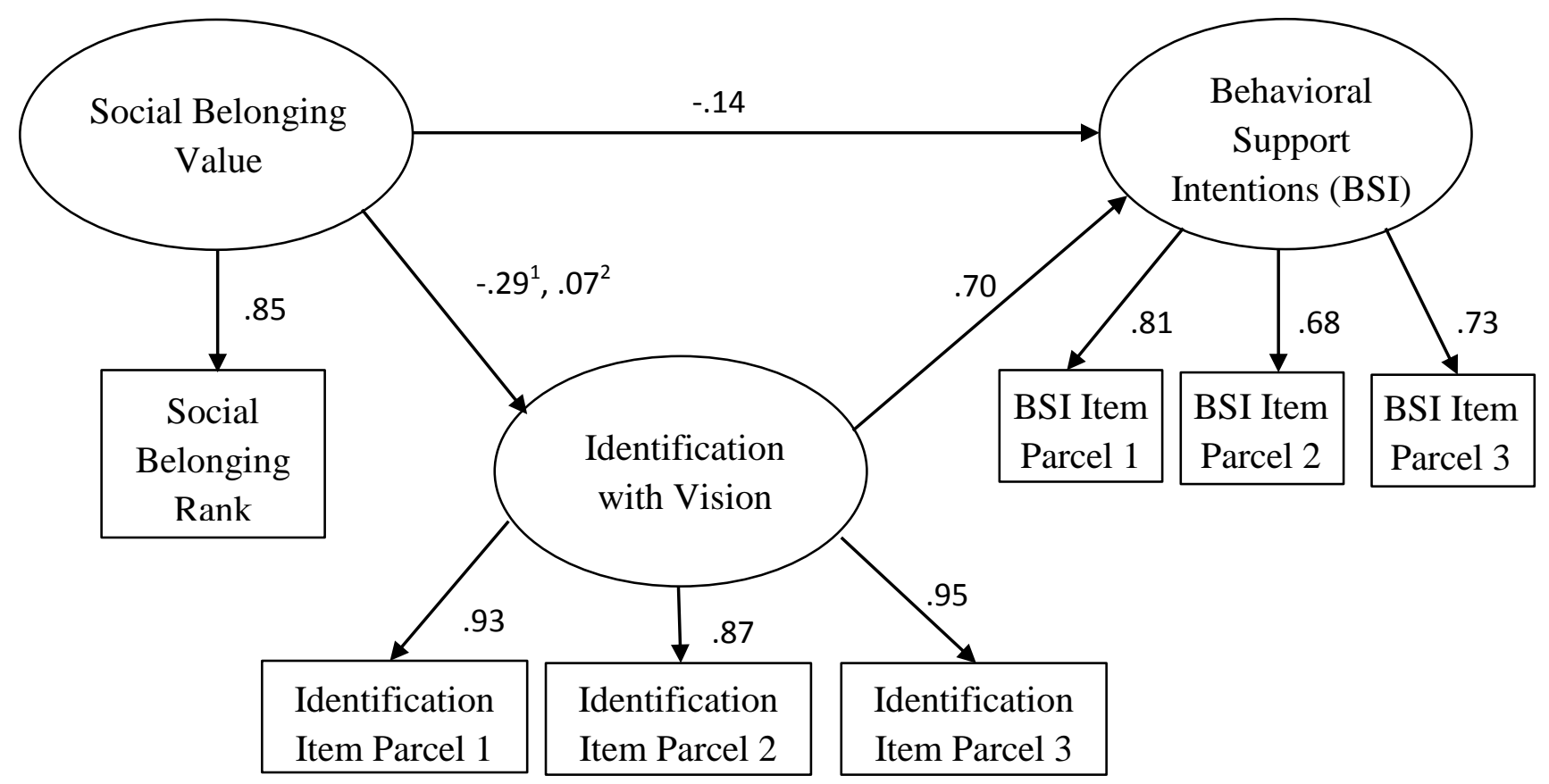

Figure 4. Structural equation model depicting identification with vision as the mediator between belonging value and behavioral support intentions.

${ }^{1}$ Relatedness Condition

${ }^{2}$ Autonomy Condition 


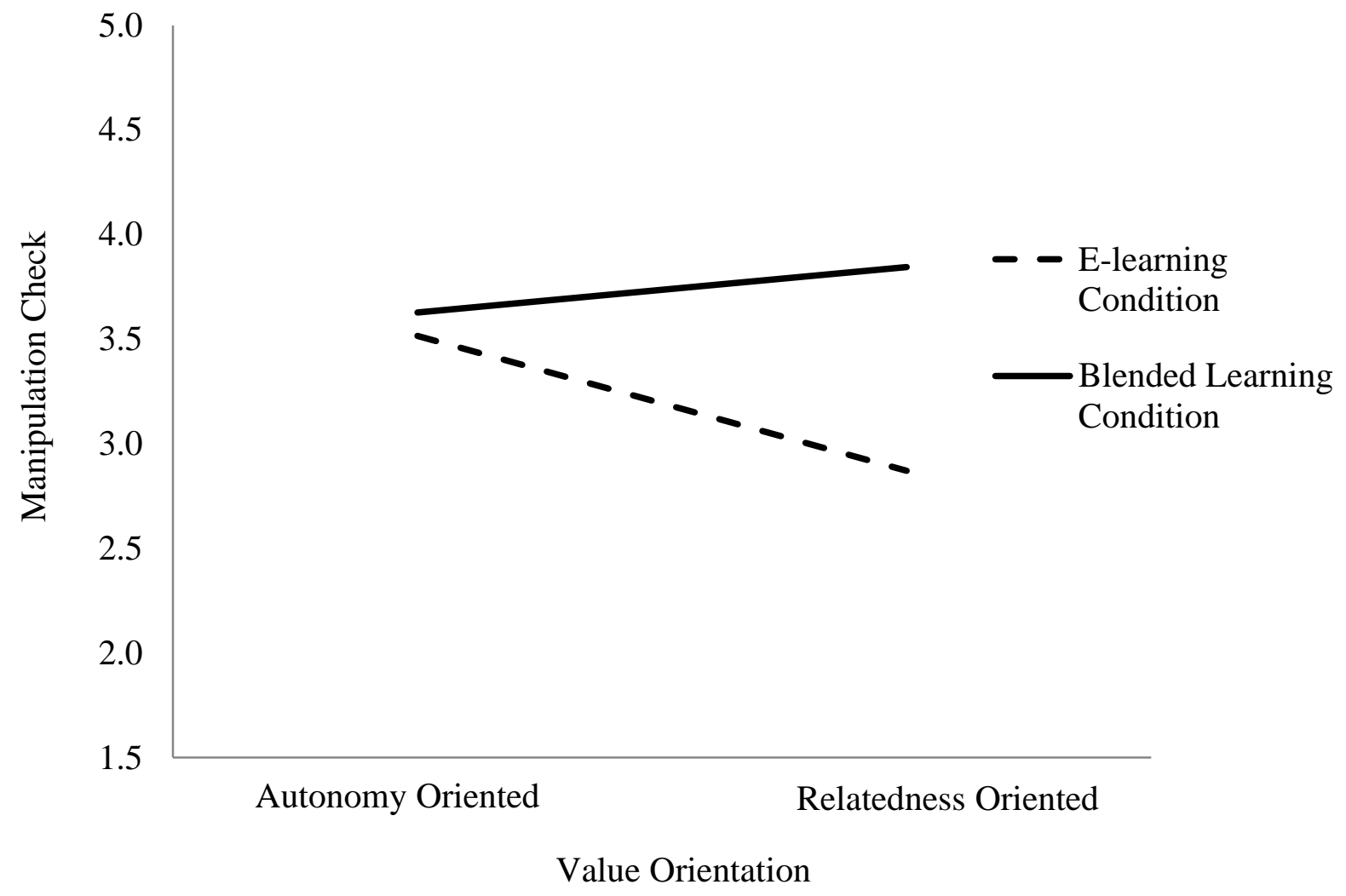

Figure 5. Interaction of value orientation $\mathrm{X}$ presentation condition on the manipulation check. 


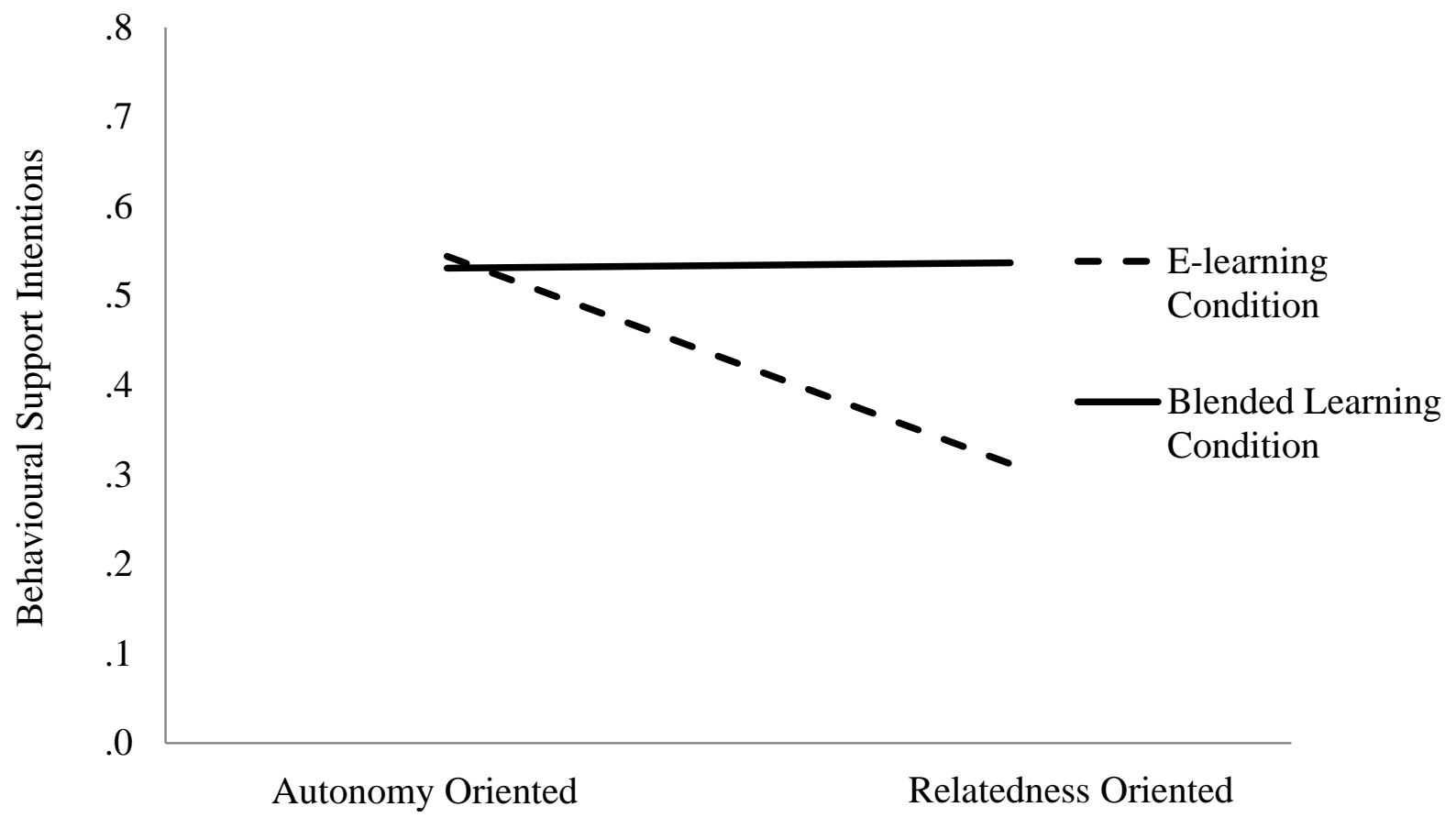

Value Orientation

Figure 6. Interaction of value orientation $\mathrm{X}$ presentation condition on behavioral support intentions. 


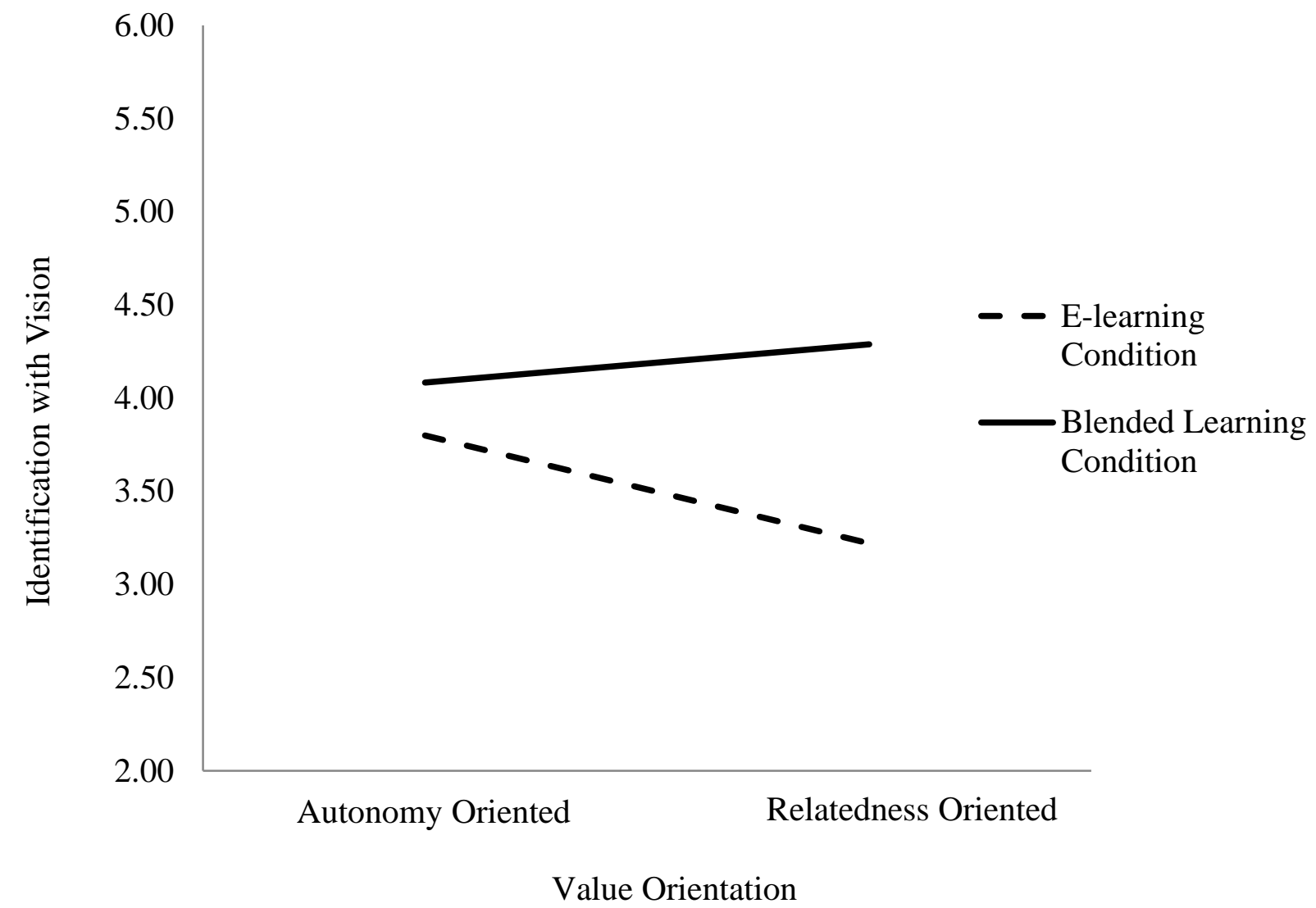

Figure 7. Interaction of value orientation $\mathrm{X}$ presentation condition on identification with vision. 


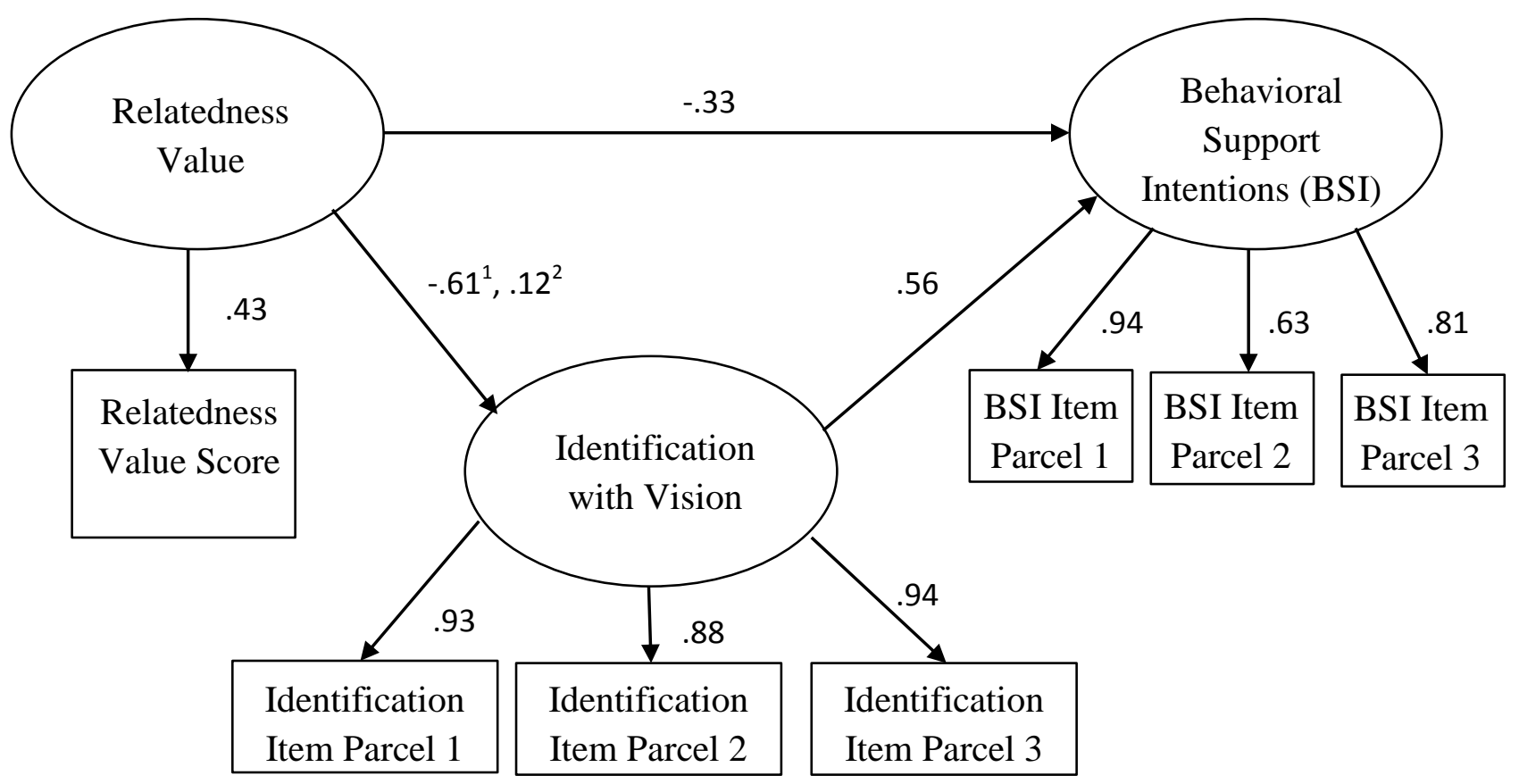

Figure 8. Structural equation model depicting identification with vision as the mediator between belonging value and behavioral support intentions in Study 2 .

${ }^{1}$ E-Learning Condition

${ }^{2}$ Blended Learning Condition 


\section{Appendix A}

Identification with the Vision

Please indicate your agreement with each statement by writing a number from the scale below in each blank on the right.

\begin{tabular}{|c|c|c|c|c|c|c|}
\hline 1 & 2 & 3 & 4 & 5 & 6 & 7 \\
STRONLY & DISAGREE & SLIGHTLY & NEUTRAL & SLIGHLTY & AGREE & STRONGLY \\
DISAGREE & & DISAGREE & & AGREE & & AGREE \\
\hline
\end{tabular}

1) Achieving this vision would have very worthwhile effects.

2) This initiative reflects what I care deeply about.

3) I would be proud if the University made this vision a reality.

4) I would think less of myself if I failed to support this initiative.

5) I would be happy to have other people know that I support this vision.

6) The goals of this initiative are very meaningful to me.

7) I strongly identify with the goals of this initiative.

8) I would feel embarrassed if the University did not support this initiative.

9) If this vision were realized, I would tell some of my friends about my support for it.

10) The ideals in the vision match up well with my own ideals. 
Appendix B

Paired Value Ranking Measure

Instructions: A number of pairs of phrases are presented below. For each pair, consider which phrase best describes values that are important to you. On the scale below the pair of phrases, select the option that indicates the degree to which one phrase describes you better than the other.

Example: Looking at phrase A and phrase B of the pair below, which one relates to you more? Then choose to what extend does the selected phrase relate to you (e.g. "describes me slightly better" to "describes me much better")

\section{Self-Reliance}

Social Connection

(Pursuing goals independently)

\begin{tabular}{|l|c|c|c|c|l|}
\hline describes me & describes me & describes me & describes me & describes me & describes me \\
much better & better & $\begin{array}{c}\text { slightly } \\
\text { better }\end{array}$ & $\begin{array}{c}\text { slightly } \\
\text { better }\end{array}$ & better & much better \\
& & & \\
\hline
\end{tabular}

\section{Self-Reliance}

(Pursuing goals independently)

\begin{tabular}{|l|c|c|c|}
\hline describes me & describes me & describes me \\
much better & better & $\begin{array}{c}\text { slightly } \\
\text { better }\end{array}$ & \\
& &
\end{tabular}

\section{Social Recognition}

(Gaining respect and admiration)
Self-Autonomy
(Being able to do things your own way)

\begin{tabular}{c|c|c|}
$\begin{array}{c}\text { describes me } \\
\text { slightly } \\
\text { better }\end{array}$ & describes me & describes me \\
better & much better \\
\hline
\end{tabular}

Sense of Belonging

(To be included, to feel connected,

to feel part of a group)

\begin{tabular}{|c|c|c|c|c|l|}
\hline describes me & describes me & describes me & describes me & describes me & describes me \\
much better & better & slightly & slightly & better & much better \\
& & better & better & & \\
\hline
\end{tabular}


(Being able to do things your own way) (Friendship, companionship, collaboration)

\begin{tabular}{|l|c|c|c|c|c|}
\hline describes me & describes me & describes me & describes me & describes me & describes me \\
much better & better & slightly & slightly & better & much better \\
& & better & better & & \\
\hline
\end{tabular}

\section{Social Connection}

Social Recognition

(Friendship, companionship, collaboration)

\begin{tabular}{|l|c|c|c|c|c|}
\hline describes me & describes me & describes me & describes me & describes me & describes me \\
much better & better & slightly & slightly & better & much better \\
& & better & better & & \\
\hline
\end{tabular}

\section{Self-Direction}

Self-Autonomy

(Choosing your own goals)

(Being able to do things your own way)

\begin{tabular}{|l|c|c|c|c|c|}
\hline describes me & describes me & describes me & describes me & describes me & describes me \\
much better & better & slightly & slightly & better & much better \\
& & better & better & & \\
\hline
\end{tabular}

Social Connection

Sense of Belonging

(Friendship, companionship, collaboration)

(To be included, to feel connected,

\begin{tabular}{|l|c|c|c|c|c|}
\hline describes me & describes me & describes me & describes me & describes me & describes me \\
much better & better & slightly & slightly & better & much better \\
& & better & better & & \\
\hline
\end{tabular}


Self-Reliance

Social Recognition

(Pursuing goals independently)

(Gaining respect and admiration)

\begin{tabular}{|l|c|c|c|c|c|}
\hline describes me & describes me & describes me & describes me & describes me & describes me \\
much better & better & slightly & slightly & better & much better \\
& & better & better & & \\
\hline
\end{tabular}

Self-Direction

Social Recognition

(Choosing your own goals)

\begin{tabular}{|l|c|c|c|c|l|}
\hline describes me & describes me & describes me & describes me & describes me & describes me \\
much better & better & slightly & slightly & better & much better \\
& & better & better & & \\
\hline
\end{tabular}

Self-Direction

Social Connection

(Choosing your own goals)

(Friendship, companionship, collaboration)

\begin{tabular}{|l|c|c|c|c|c|}
\hline describes me & describes me & describes me & describes me & describes me & describes me \\
much better & better & slightly & slightly & better & much better \\
& & better & better & & \\
\hline
\end{tabular}

Self-Autonomy

Social Recognition

(Being able to do things your own way) (Gaining respect and admiration)

\begin{tabular}{|l|c|c|c|c|c|}
\hline describes me & describes me & describes me & describes me & describes me & describes me \\
much better & better & slightly & slightly & better & much better \\
& & better & better & & \\
\hline
\end{tabular}

Self-Reliance

Sense of Belonging

(Pursuing goals independently)

(To be included, to feel connected,

\begin{tabular}{|l|c|c|c|c|c|}
\hline describes me & describes me & describes me & describes me & describes me & describes me \\
much better & better & slightly & slightly & better & much better \\
& & better & better & & \\
\hline
\end{tabular}


Self-Direction

Self-Reliance

(Choosing your own goals)

(Pursuing goals independently)

\begin{tabular}{|l|c|c|c|c|c|}
\hline describes me & describes me & describes me & describes me & describes me & describes me \\
much better & better & slightly & slightly & better & much better \\
& & better & better & & \\
\hline
\end{tabular}

Self-Direction

Sense of Belonging

(Choosing your own goals)

(To be included, to feel connected,

to feel part of a group)

\begin{tabular}{|l|c|c|c|c|c|}
\hline describes me & describes me & describes me & describes me & describes me & describes me \\
much better & better & slightly & slightly & better & much better \\
& & better & better & & \\
\hline
\end{tabular}

Self-Autonomy

Sense of Belonging

(Being able to do things your own way)

(To be included, to feel connected,

to feel part of a group)

\begin{tabular}{|l|c|c|c|c|c|}
\hline describes me & describes me & describes me & describes me & describes me & describes me \\
much better & better & slightly & slightly & better & much better \\
& & better & better & & \\
\hline
\end{tabular}

